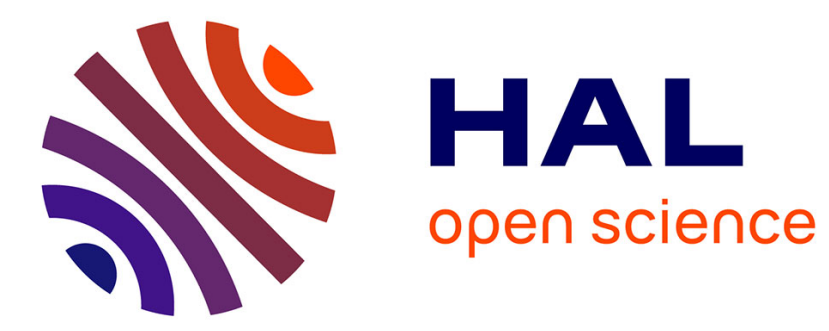

\title{
A tetrachlorocobaltate(II) salt with 2-amino-5-picolinium Synthesis, theoretical and experimental characterization
}

\author{
M. Tahenti, S. Gatfaoui, N. Issaoui, T. Roisnel, H. Marouani
}

\section{To cite this version:}

M. Tahenti, S. Gatfaoui, N. Issaoui, T. Roisnel, H. Marouani. A tetrachlorocobaltate(II) salt with 2-amino-5-picolinium Synthesis, theoretical and experimental characterization. Journal of Molecular Structure, 2020, 1207, pp.127781. 10.1016/j.molstruc.2020.127781 . hal-02472932

\section{HAL Id: hal-02472932}

\section{https://hal-univ-rennes1.archives-ouvertes.fr/hal-02472932}

Submitted on 28 May 2020

HAL is a multi-disciplinary open access archive for the deposit and dissemination of scientific research documents, whether they are published or not. The documents may come from teaching and research institutions in France or abroad, or from public or private research centers.
L'archive ouverte pluridisciplinaire HAL, est destinée au dépôt et à la diffusion de documents scientifiques de niveau recherche, publiés ou non, émanant des établissements d'enseignement et de recherche français ou étrangers, des laboratoires publics ou privés. 


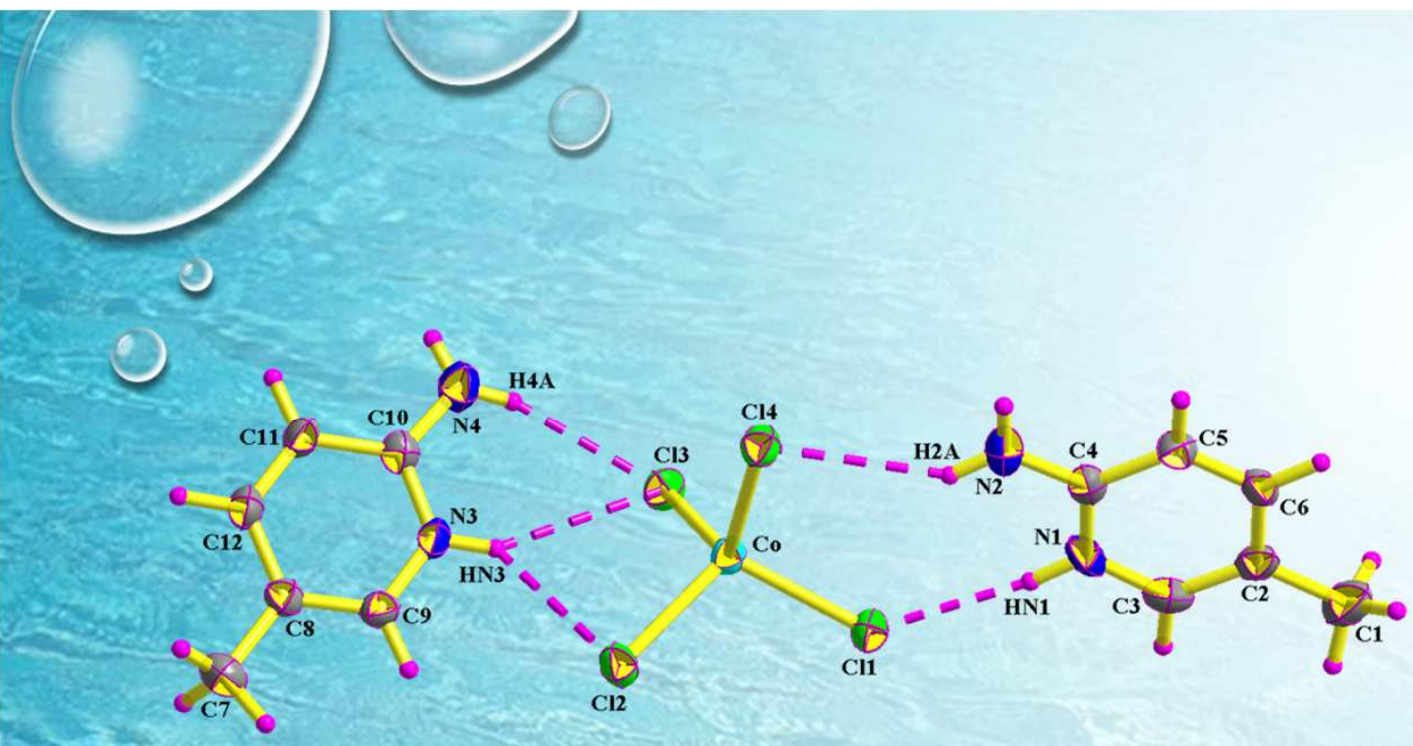

$$
\sum_{0}
$$

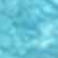

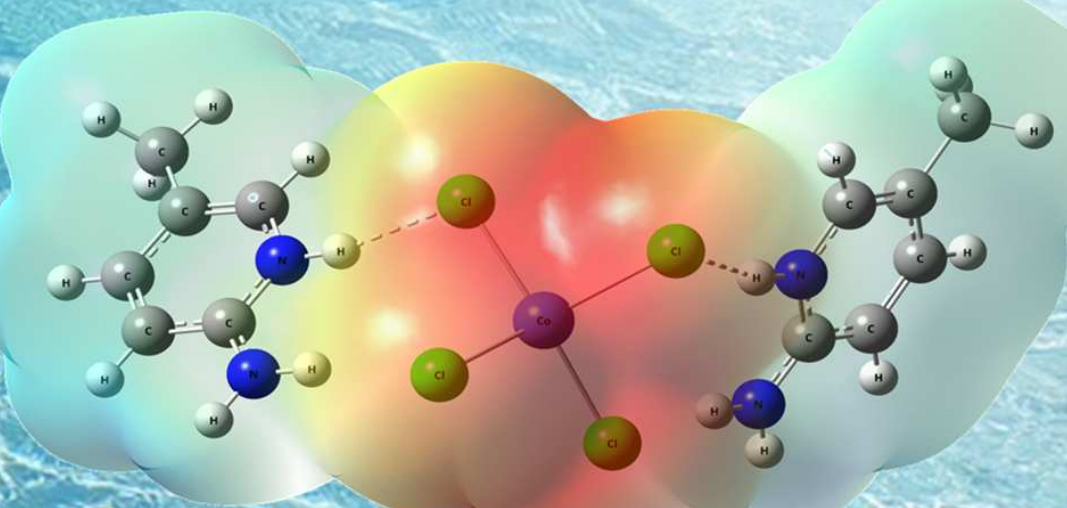
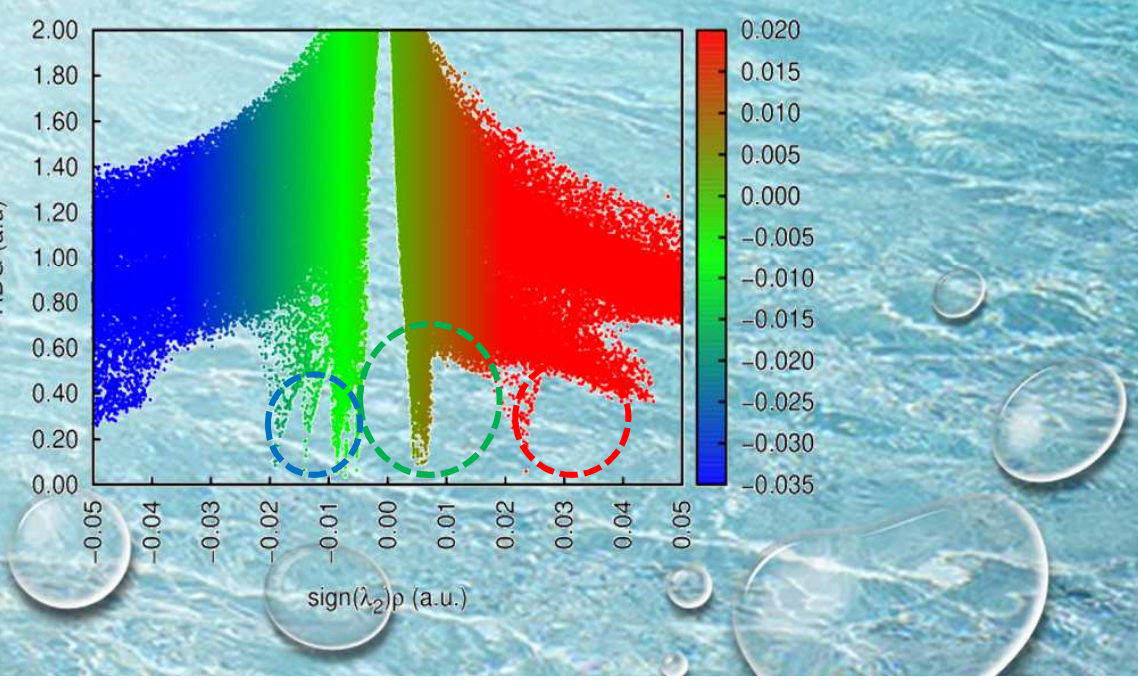

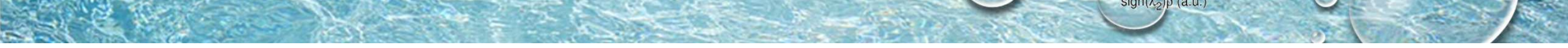




\title{
A tetrachlorocobaltate(II) salt with 2-amino-5-picolinium: synthesis, theoretical and experimental characterization
}

\author{
Mariem Tahenti ${ }^{(a)}$, Sofian Gatfaoui ${ }^{(a)}$, Noureddine Issaoui ${ }^{(b)}$, Thierry Roisnel ${ }^{(c)}$, Houda \\ Marouani $^{(a)} *$
}

(a) Université de Carthage, Faculté des Sciences de Bizerte, Laboratoire de Chimie des Matériaux (LR13ES08), 7021 Bizerte, Tunisia

(b) University of Monastir, Faculty of Sciences, Laboratory of Quantum and Statistical Physics (LR18ES18), Monastir 5079, Tunisia

(c) Univ Rennes, CNRS, ISCR (Institut des Sciences Chimiques de Rennes) - UMR 6226, F-35000 Rennes, France

*Corresponding author: houdamarouani2015@gmail.com

\begin{abstract}
The novel complex, (2-amino-5-picolinium) tetrachlorocobaltate(II), (2A5PCoCl 4$)$ have been synthesized and crystallized to the monoclinic system with space group $\mathrm{P} 2{ }_{1} / \mathrm{c}$ and the lattice parameters obtained are $a=8.0734$ (6) $\AA, b=14.6297$ (11) $\AA, c=15.6913$ (11) $\AA, \beta=103.034$ (4) ${ }^{\circ}, V=1805.6$ (2) $\AA^{3}$ and $Z=4$. His atomic arrangement can be described as an alternation of inorganic and organic layers, $\left[\mathrm{CoCl}_{4}\right]^{2-}$ tetrahedral anions and 2-amino-5picolinium cations are connected by bifurcated and no-bifurcated $\mathrm{N}-\mathrm{H}$...Cl and $\mathrm{C}-\mathrm{H} . . \mathrm{Cl}$ hydrogen bonds. The intermolecular interactions in the crystal structure were quantified by using the three-dimensional Hirshfeld surfaces and two-dimensional fingerprint plots and interactions were analyzed by topological AIM, RDG and NBO approaches. Infrared spectrum confirms the existence of functional groups and used to gain more information of the elaborated material. The DTA/TG analyses were accomplished to inspect the thermal stability of $2 \mathrm{~A} 5 \mathrm{PCoCl}_{4}$.
\end{abstract}

Keywords: X-ray diffraction; DFT calculations; Hirshfeld surface; AIM; IR spectroscopy 


\section{Introduction}

An hybrid material is qualified when it comprises both organic and inorganic entities. Hybrids are very interest because of their wide range of technologically advantageous properties, their amazing composition and their exceptional structural diversity.

Thus, following the structural integration of organic cations and inorganic counterparts, electrical [1,2], magnetic [3,4], optical [5], and electroluminescence [6], as well as their ionic properties $[7,8]$ appeared in this class of hybrid chemical systems, and penetrate several application fields such as optic, solid electrolytes, catalysis, biomaterials and biomedical applications $[9,10]$.

The contribution of this work is on hybrid materials base on halogenometalate, have several advantages like include good electric mobility, tunable band gap and magnetic properties, and thermal stability [11] especially that based on cobalt(II).

The coordination numbers of inorganic compound can be three, four (tetrahedral) [12], five (trigonal bipyramidal), or six (octahedral) [13]. To date, salts of general formula $\left[\mathrm{CoX}_{4}\right]^{2-}$ anion and organic cations (where $\mathrm{X}=\mathrm{Cl}, \mathrm{Br}$ ), have been an interesting area of chemistry and have been extensively studied using spectroscopic in the literature [14], another purpose was to explore thermal [5] and magnetic [15] properties.

Particularly in recent years, much interest has been paid to the study of cobalt(II) halide salts containing tetrahedral $\mathrm{CoX}_{4}$ geometries. However, the studies concerning this kind of hybrid material is still rare so far except of studies on structural phase transition and magnetic properties of these crystals [16].

In contrast, the hybrids based on cobalt halide possess good solubility and stability. The use of hydrogen bonding interactions with metal salts (such as $\mathrm{N}-\mathrm{H}$...Cl hydrogen bonds) to control the crystal structure product has also recently received attention [14-17].

Considering the attractive and the attributes of halogenocobaltate(II), the present work reports on chemical preparation, crystal structure study of $\left(\mathrm{C}_{6} \mathrm{H}_{9} \mathrm{~N}_{2}\right)_{2}\left[\mathrm{CoCl}_{4}\right]$ compound by Hirshfeld analysis, intermolecular interactions were studied by NBO and AIM analyses, infrared spectroscopy, thermal analysis of a novel organic tetrachlorocobaltate(II) have been investigated. 


\section{Experimental section}

\subsection{Materials}

The cobalt chloride hexahydrate was a commercial product (Sigma-Aldrich), the amine 2-amino-5-picoline was a commercial product (Accros), as well as the Hydrochloric acid $(\mathrm{HCl} ; 37 \%)$ was commercial by OXFORD.

\subsection{Synthesis of $\left(\mathrm{C}_{6} \mathrm{H}_{9} \mathrm{~N}_{2}\right)_{2}\left[\mathrm{CoCl}_{4}\right]$}

The new compound $\left(\mathrm{C}_{6} \mathrm{H}_{9} \mathrm{~N}_{2}\right)_{2}\left[\mathrm{CoCl}_{4}\right]$ was obtained by slow evaporation, at room temperature. $\left(\mathrm{C}_{6} \mathrm{H}_{8} \mathrm{~N}_{2}\right)$ was dissolved with either $\mathrm{CoCl}_{2} \cdot 6 \mathrm{H}_{2} \mathrm{O}$ in $10 \mathrm{~mL}$ of distilled water and hydrochloric acid $\mathrm{HCl}(\mathrm{pH}<2.5)$ with metal/amine molar ratio 1:2. The clear solutions were stirred for $10 \mathrm{~min}$ until the complete dissolution and allowed to stand at room temperature. The crystals with the specific color of the metal appeared after few days. Then, the product was filtered off and washed with a small amount of distilled water before being dried in ambient air.

$$
2\left(\mathrm{C}_{6} \mathrm{H}_{8} \mathrm{~N}_{2}\right)+\mathrm{CoCl}_{2} \cdot 6 \mathrm{H}_{2} \mathrm{O}+2 \mathrm{HCl} \stackrel{\mathrm{T}=25^{\circ} \mathrm{C}}{\longrightarrow}\left(\mathrm{C}_{6} \mathrm{H}_{9} \mathrm{~N}_{2}\right)_{2}\left[\mathrm{CoCl}_{4}\right]+6 \mathrm{H}_{2} \mathrm{O}
$$

Crystallographic data (CIF) for the structure reported in this paper have been deposited in the Cambridge Crystallographic Data center as supplementary materials $\mathrm{N}^{\circ} 1942470$ CCDC. Copies of the data can be obtained free of charge, from the Cambridge Crystallographic Data centre via www.ccdc.cam.ac.uk/data_request/cif.

\subsection{Investigation techniques}

\subsubsection{X-ray crystallography}

Small crystal of $2 \mathrm{~A} 5 \mathrm{PCoCl}_{4}$, was chosen for measurements on a diffractometer APEXII, Bruker-AXS with MoK $\alpha$ radiation $(\lambda=0.71073 \AA$ A). Data collection, absorption collections frame scaling and unit cell parameters refinements were carried out with multi scan technique with the SADABS program [18]. The total number of measured reflections was 15135 reflections which 4139 was independent and 3126 reflections with $\mathrm{I}>2 \sigma(\mathrm{I})$. The structure an analysis was carried with the monoclinic symmetry, space groups $\mathrm{P} 2{ }_{1} / \mathrm{c}$, according to the automated search for space group available in WinGX [19]. This structure was solved with direct methods using SHELXL-97 [20]. H atoms bonded to $\mathrm{C}$ atoms were positioned geometrically and allowed to ride on their parent atoms, with $\mathrm{C}-\mathrm{H}=0.95$. The hydrogen atoms bonded to nitrogen atoms were located from a difference map. The drawing 
was made with DIAMOND program [21]. A final refinement on $\mathrm{F}^{2}$ converged at $\mathrm{R}\left(\mathrm{F}^{2}\right)=$ 0.033 and $\mathrm{wR}\left(\mathrm{F}^{2}\right)=0.076$. The main crystallographic data and refinement parameters are presented in Table 1. An ORTEP [19] drawing of the molecular structure is shown in Fig. 1a.

\subsubsection{Physical measurements}

IR measurement was performed using a spectrometer. Sample was dispersed with spectroscopic $\mathrm{KBr}$ and pressed into a pellet. Scans were run over the range $400-4000 \mathrm{~cm}^{-1}$. The thermal analyses TG-DTA measurements was performed using a multimodule 92 setaram analyzed operating from $313 \mathrm{~K}$ up to $880 \mathrm{~K}$ in a platinum crucible at an average heating rate of $5 \mathrm{~K} \cdot \mathrm{min}^{-1}$ and the mass of the sample was $12.4 \mathrm{mg}$.

\subsubsection{Theoretical studies}

The intermolecular interactions were also studied by Hirshfeld surface analysis which was carried out using the Crystal Explorer 3.1 software [22] imported on a CIF file. The theoretical calculations have been performed with the Gaussian 09 software package [23] by using the Density functional theory (DFT) with the Becke-three-parameter hybrid exchange functional combined with the Lee-Yang-Parr correlation functional (B3LYP) [24, 25] levels, the 6-311++G(d,p) basis set was used for all atoms except for the cobalt atom, the LANL2DZ basis set and effective core potentials (ECPs) have been used in order to represent the metal. The GaussView was used as molecular visualization program [26]. All the calculations have converged to an optimized geometry that corresponds to the lowest energy. Positive vibrational frequencies obtained confirming the stability of the optimized geometries.

The vibrational assignments were performed considering the potential energy distribution components (PED) $\geq 10 \%$ using the VEDA4 package [27]. The GaussView package was used to verify the assignments of the bands. In this study, NBO calculations [28] were employed to determinate the energy of intermolecular interactions, furthermore topological proprieties were determined with the Mutiwfn program [29] in accordance with the Bader's theory [30]. The results were plotted by the use of VMD programs [31].

\section{Results and discussion}

\subsection{X-ray diffraction}


The asymmetric unit of the title material, $\mathrm{C}_{12} \mathrm{H}_{18} \mathrm{~N}_{4}{ }^{2+} \cdot \mathrm{CoCl}_{4}{ }^{2-}$ contains one tetrachlorocobaltate anion and two 2-amino-5-picolinium cations. The optimized geometry model of this compound is illustrated in Fig. $\mathbf{1 b}$.

The $\mathrm{Co}(\mathrm{II})$ ion is tetrahedrally bound by four chlorine atoms, with $\mathrm{Co}-\mathrm{Cl}$ bond distances ranging from 2.2473 (8) to 2.2953 (7) $\AA$ and $\mathrm{Cl}-\mathrm{Co}-\mathrm{Cl}$ bond angles between $105.23(3)^{\circ}$ and $113.76(3)^{\circ}$ which are slightly deviated from the ideal value of $109.44^{\circ}$ (Table S1). In the other hand, we propose a very simple geometry index in four-coordinate complex, $\tau_{4}($ eqn (1)).

$$
\tau_{4}=\frac{360-(\alpha+\beta)}{141^{8}}
$$

The formula for our four-coordinate index $\tau_{4}$ is simply the sum of angles $\alpha$ and $\beta$ the two largest $\theta$ angles in the four-coordinate species subtracted from $360^{\circ}$, all divided by $141^{\circ}$. Indeed, the four-coordinate cobalt(II) geometry index [32] provides a slightly distorted tetrahedral geometry of $\left[\mathrm{CoCl}_{4}\right]^{2-}$.

$$
\tau_{4}=\frac{360-(113,76+111,63)}{141}=0.95
$$

Indeed, the calculated average values of the distortion indices corresponding to the different angles and distances in the $\mathrm{CoCl}_{4}$ tetrahedra according to the method described by Baur [33] are: $[\mathrm{DI}(\mathrm{CoCl})=0.0372 ; \mathrm{DI}(\mathrm{ClCl})=0.00632$ and $\mathrm{DI}(\mathrm{ClCoCl})=0.01976]$. The comparison of the distortion indices shows a small distortion of the $\mathrm{Cl}-\mathrm{Co}-\mathrm{Cl}$ angles with respect to the $\mathrm{Co}-\mathrm{Cl}$ distances from which the $\left[\mathrm{CoCl}_{4}\right]^{2-}$ anion has a tetrahedral geometry. It can be admitted that the $\mathrm{CoCl}_{4}$ tetrahedron is formed by a regular arrangement of chlorine atoms, in which the cobalt atom is slightly displaced from the center of gravity of the tetrahedron.

The projection in the direction of the $\overrightarrow{\boldsymbol{a}}$ axis (Fig. 2a), can be described by a succession of anion-cation layered arrangement which alternate along of the $\vec{c}$ axis and unfold parallel to the $\overrightarrow{\boldsymbol{b}}$ axis. On the same projection we can also notice that the mineral anions develop in zigzag along the $\vec{b}$ axis in $\mathrm{z}=1 / 4$ and $3 / 4$, and the organic cations propagate in inclined rows along the $\overrightarrow{\boldsymbol{c}}$ axis $\mathrm{z}=1 / 2$. The cohesion of these layers is ensured by medium and weak hydrogen bonds which connect the $\left[\mathrm{CoCl}_{4}\right]^{2-}$ and the 2-amino-5-picolinium cations. To 
better understand the mode of arrangement of organic and inorganic entities in such an atomic arrangement, the structure is still projected in the direction of the axis $\overrightarrow{\boldsymbol{c}}$ (Fig. 2b). The projection of the anionic part $\left[\mathrm{CoCl}_{4}\right]^{2-}$ on the $(\mathrm{ab})$ plane shows that the latter develops in a chain according to the two directions $\vec{a}$ and $\vec{b}$, in the same figure we notice that each anion $\left[\mathrm{CoCl}_{4}\right]^{2-}$ connects to four other anions through type hydrogen bonds $\mathrm{N}-\mathrm{H}$... Cl thus forming a type of graphs $R_{8}^{7}(22)$ (Fig. 2c). The interatomic distances and the bonding angles of $\left(\mathrm{CoCl}_{4}\right)$ collected in Table S1 do not show any particularity compared to those generally encountered in organic tetrachlorocobaltate known until now [34]. Concerning the organic cation, the geometric characteristics classified in Table S1 are found in agreement with those observed for the same cation crystallizing with other types of anions [35]. The Hydrogen bonds N$\mathrm{H}$... Cl involving the hydrogen atoms of the ammonium groups of the organic entities to the chlorine atoms of the anionic group (Table 2) their distances $d_{\mathrm{N}} \ldots \mathrm{Cl}$ are varying between 3.214 (2) $\AA$ and 3.478 (2) $\AA$. We notice the appearance of the graphs $R_{2}^{2}(8), R_{1}^{2}(4)$ and $R_{2}^{1}(6)$. Three bonds of type $\mathrm{C}-\mathrm{H} . . . \mathrm{Cl}$ attach the organic groups and the anionic groups $\left[\mathrm{CoCl}_{4}\right]^{2-}$ their average distance $\mathrm{d}_{\mathrm{C} . . . \mathrm{Cl}}$ is $3.719 \AA$.

The geometric parameters studied experimentally by X-ray diffraction, and theoretically by DFT(B3LYP/LANL2DZ), such as the bond lengths and the angles of the $2 \mathrm{~A} 5 \mathrm{PCoCl}_{4}$ are tabulated in Table S1. Optimized molecular structure gives a comparison between the optimized geometric parameters and experimental X-ray crystallographic parameters. From this table, the $\mathrm{C}-\mathrm{C}$ linkages in the pyridine of the 2-amino-5-picolinium group were calculated at the range of $1.384 \AA-1.512 \AA$ which is compatible with other pyridine rings [36]. The average value of calculated bond length of $\mathrm{C}-\mathrm{H}$ an $\mathrm{N}-\mathrm{H}$ is equal to $1.1 \AA$ relative to the mean value observed by experimentally of 1.01 . As regards the anionic group, we have a slightly difference in values because the investigational results characterize molecules at solid state; however the theoretical calculations refer to isolated molecules in the gas phase. Lastly, it can be noted that in spite of the differences between the experimental and optimal results, the second represent an excellent estimation.

\subsection{Hirshfeld surface analysis}

The Hirshfeld $\mathrm{d}_{\text {norm }}$ surface of $2 \mathrm{~A} \mathrm{PCoCl}_{4}$ is illustrated in Fig. 3a also the shape index and the curvedness cartography are shown respectively in Figs. $\mathbf{3 b}$ and $\mathbf{3 c}$. This analysis can be done by quantitative calculation of 2D fingerprint plots through the CrystalExplorer 3.1 program [22]. The full fingerprint plot and the fingerprints plots of the main contacts involved 
in this compound are illustrated in Fig. 4. At each point of the Hirshfeld surface is associated a $d_{e}$ and $d_{i}$ value. For a pair $\left(d_{i}, d_{e}\right)$, the sum of these components is equal to the distance separating the atoms contributing to this point.

The interatomic contacts $\mathrm{H}$...Cl/Cl...H have the greatest contribution to the Hirshfeld surface $(42 \%)$, attributed to the $\mathrm{N}-\mathrm{H} \ldots \mathrm{Cl}$ and $\mathrm{C}-\mathrm{H} \ldots \mathrm{Cl}$ hydrogen-bonding interactions and represented by two sharp symmetric spikes in the two-dimensional fingerprint maps, with a maximum $\boldsymbol{d}_{\boldsymbol{e}}+\boldsymbol{d}_{\boldsymbol{i}} \sim \mathbf{2 , 3 0} \AA$ (Fig. 4a). This value is less than the sum of van der Waals radii of chlorine $(1,75 \AA)$ and hydrogen $(1,09 \AA)$ atoms; it confirms that the inter-contact is considered as being close contact. The fingerprint plots corresponding to the contacts C...C (1.9\%) (Fig. 4f) shows that the sum $\left(d_{i}+d_{e} \sim 2.5 \AA\right)$ smaller than the sum of the van der Waals radii of the carbon atoms (3.4 $\AA$ ) confirm the presence of $\pi-\pi$ interactions in the crystalline stack. This is also confirmed by the presence of the red and blue triangles on the Shape index cartography (Fig.3b) and in the plane regions delimited by a blue outline on the Hirshfeld surfaces mapped with Curvedness (Fig. 3c).

The enrichment ratio (ER) of a pair of elements is defined as the ratio between the percentage of the actual contacts in the crystal and the theoretical percentage of the random contacts [37]. The set of enrichment ratios of the various intermolecular contacts occurring in the $2 \mathrm{~A}_{5} \mathrm{PCoCl}_{4}$ compound are recorded in Table S2. The list of enrichment ratios highlights the contacts $\mathrm{H} \ldots \mathrm{Cl} / \mathrm{Cl} \ldots \mathrm{H}\left(\mathrm{ER}_{\mathrm{HCl}}=1.47\right)$ clearly provides evidence of the formation of hydrogen bonds of type $\mathrm{N}-\mathrm{H} \ldots \mathrm{Cl}$ and $\mathrm{C}-\mathrm{H} \ldots \mathrm{Cl}$. The $\mathrm{H}$...H contacts are the second most frequent interactions due to the large quantity of hydrogen on the molecular surface $(34.2 \%)$, but they have too small degree figured with an enrichment ratio of 0.84 . The ER relates to the contacts of $\mathrm{Cl}$... Cl and $\mathrm{Cl}$... $\mathrm{C} / \mathrm{C} \ldots \mathrm{Cl}$ are of low meaning as they are derived from less important interactions with small contributions in the all parts Hirshfeld surface. The contacts $\mathrm{C} \ldots \mathrm{H} / \mathrm{H} \ldots \mathrm{C}$ have an enrichment ratio equal to 0.98 , which also proves the presence of the interactions $\mathrm{C}-\mathrm{H} \ldots \pi[37,38]$.

Such visual analysis for intermolecular interactions is coherent with those noticed by the X-ray diffraction analysis.

\subsection{AIM topological, reduced density gradient (RDG) and NBO analyses}

The AIM approach consists of defining the different properties of chemical bonds, including hydrogen bonds. For this purpose, the critical point BCP is used for the 
identification of the chemical bonds between the atoms and the interatomic interaction. Geometric and topological parameters are an effective way to characterize the strength and nature of the $\mathrm{H}$ bond, but these criteria for the existence of hydrogen bonds are often considered insufficient, so we must rely on Koch and Popelier [39] to confirm the existence of a hydrogen bond, therefore these criteria are the existence of a critical binding point for the contact of the proton acceptor $\mathrm{H}$ (A), thus confirming the existence of a hydrogen bonding interaction, these criteria are the existence of a critical binding point for the proton (A) acceptor contact $(\mathrm{H})$ confirming the existence of a hydrogen bonding interaction, the value of the electron density $\rho(\mathrm{H} . . . \mathrm{A})$ must be in the range of 0.002 to $0.004 \mathrm{a}$.u, the corresponding Lapalcian is positive in the range of 0.024 to 0.0139 a.u according to Rozas et al. [40], the interaction can be classified as follows:

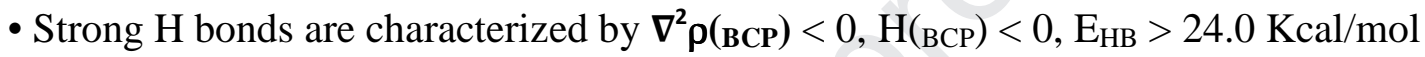
and their covalent character is established.

- Moderate $\mathrm{H}$ bonds are characterized by $\boldsymbol{\nabla}^{2} \rho(\mathbf{B C P})>0, \mathrm{H}\left({ }_{\mathrm{BCP}}\right)<0,12.0<\mathrm{E}_{\mathrm{HB}}<24.0$ $\mathrm{Kcal} / \mathrm{mol}$ and their partially covalent character is established.

- The weak $\mathrm{H}$ bonds are characterized by $\boldsymbol{\nabla}^{2} \boldsymbol{\rho}(\mathbf{\text { вср }})>0, \mathrm{H}\left({ }_{\mathrm{BCP}}\right)>0, \mathrm{E}_{\mathrm{HB}}<12.0$ $\mathrm{Kcal} / \mathrm{mol}$ and they are mainly electrostatic and the distance between the interacting atoms is greater than the sum of the van der Waals rays of these atoms.

The graphical representation of AIM analysis of $2 \mathrm{~A}^{5} \mathrm{PCoCl}_{4}$ is illustrated in Fig. 5, whereas the calculated topological parameters are listed in Table S3. According to this table, $\mathrm{Cl} 36$... H9, $\mathrm{Cl} 37$... H24, Cl37 ... H26, Cl37 ... H17, Cl38 ... H24, Cl38 ... H33 and $\mathrm{Cl} 39$... H17 are weak hydrogen bonds. AIM analysis shows that our material is stable by two hydrogen bonds $\mathrm{Cl}$... H. In this study, the BCPs along $\mathrm{Cl}$...H and the Laplacian of the total electron density $\nabla \rho\left(\mathrm{r}_{\mathrm{BCP}}\right)$ are between 0.0238 and 0.0576 a.u with electron energy densities $\mathrm{H}\left(\mathrm{r}_{\mathrm{BCP}}\right)$ between 0.0009 and 0.0284 a.u respectively for the two hydrogen bonds $\mathrm{N} 32 \ldots \mathrm{H} 33$ and $\mathrm{N} 25 . . . \mathrm{H} 26$. The energy of the hydrogen bond is calculated using the Espinosa relation [41]: $\mathrm{E}_{\mathrm{Cl} \ldots \mathrm{H}}=1 / 2 \mathrm{~V}_{\mathrm{BCP}}$. Therefore the hydrogen bond energies of our compound vary between -14.10 and $-3.24 \mathrm{~kJ} / \mathrm{mol}$. In our case, based on the energy density values of the topological parameters, it can be concluded that the bonds are weak bonds since the values of the Laplacian and the density of the total energy are positive. The AIM confirms the presence of the H...H contacts already observed by Hirshfeld surface analysis, so the existence of its intermolecular interactions is also a proof of the critical points BCP. In addition, the presence 
of a new ring critical point 'RCP' confirms the cyclic character of an atomic chain. As shown in Fig. 5, the interactions between the organic group and the $\left[\mathrm{CoCl}_{4}\right]^{2-}$ anion via hydrogen bonds give rise to the formation of the rings NRCP1 and NRCP2.

The existing intermolecular interactions in $2 \mathrm{~A} 5 \mathrm{PCoCl}_{4}$ compound experimentally processed by X-ray diffraction and confirmed theoretically by Hirshfeld surface analysis, geometric optimization and by AIM topological analysis, have been also validated and evaluated using the multi-wavefunction analysis, this latter was carried out by a RDG plot analysis and isosurface of interactions. The RDG approach is a dimensionless elementary amount obtained from the density and its first derivative developed by Johnson et al. [42]:

$$
\mathrm{RDG}(\mathrm{r})=\frac{1}{2\left(3 \pi^{2}\right)^{1 / 3}} \frac{\mid \sigma \rho(r)]}{\rho(n) / 3}
$$

Based on the density $\rho(\mathrm{r})$ against sign $\lambda_{2}$ we have tried to understand and indicate the nature of strength of the different interactions existing in our crystalline structure:

- If $\lambda_{2}<0$ : Attractive and binding interactions (hydrogen bonds).

- If $\lambda_{2}>0$ : repulsive and non-binding interactions (steric effect in ring and cage).

- Values close to zero indicating van der Waals interactions.

The results were collected in Figs. $6 \mathbf{a}$ and $\mathbf{6 b}$ and illustrate the attractive, van der Waals and repulsive interactions in our compound structure. The interactions appear in the form of green plates are attributed to van der Waals interactions; its plates are located exactly between the hydrogen and the chlorine atoms. The elliptic red plate located at the center of the aromatic nucleus [43] is related to $\pi-\pi$ stacking interactions between the pyridine rings and show a strong steric effect. The green plates signifie the strong attractive interaction $\mathrm{N}-\mathrm{H} \ldots \mathrm{Cl}$ and $\mathrm{C}-\mathrm{H} \ldots \mathrm{Cl}$. The RDG peak at -0.22 corresponds to a strong interaction between chlorine and hydrogen, which was also confirmed by the blue color in the color scaling. These results are comparable to those found in the AIM calculation and in other previous researches [4445].

Natural bond analysis (NBO) is a powerful method that allows us to study and identify the specific bonds and energies associated with one-pair electrons, which play a very important and essential role in physico-chemical processes [46]. This method has been used to establish electronic exchanges, transfer reactions, hydrogen bonding between donor-acceptor 
compounds and hyperconjugative interactions. The difference of energy between interacting orbitals give an idea for the interaction force between acceptor electrons and donor electrons or otherwise the stability of the orbital interactions. The most stable interaction can be estimated by calculating the second-order stabilization energy $\mathrm{E}^{(2)}$ [47]:

$$
E^{(2)}=q_{i} \frac{\left.F^{2}\left(i_{j}\right)\right)}{\varepsilon_{i}-\varepsilon_{j}}
$$

Where $\mathrm{q}_{\mathrm{i}}$ is the occupation of $\mathrm{i}$ orbital, $\varepsilon_{\mathrm{i}}$ and $\varepsilon_{\mathrm{j}}$ are the diagonal elements of orbital energies $i$ and $j$ and $F(i, j)$ is the Fock matrix element outside diagonal. The value of $E^{(2)}$ energy is directly related to the intensity of interaction between donor and electron acceptor, more $\mathrm{E}^{(2)}$ is large more the interaction between donor and electrons acceptor is intense.

Table S4 presents the stabilization energies $\mathrm{E}^{(2)}$, which indicate the electron delocalization from the donor NBO to acceptor. It is noticed that hydrogen bond interactions between the lone pair LP $(\mathrm{Cl} 36)$ orbital and the $\sigma^{*}$ (N8-H9) antibonding orbital with stabilization energy equal to $9.71 \mathrm{kcal} \mathrm{mol}^{-1}$, this is reflected by the strong interaction between the anionic and cationic groups which is manifested by the formation of a hydrogen bond N8$\mathrm{H} 9 . . \mathrm{Cl} 36$. The stabilization energy $\mathrm{E}^{(2)}$ of the hyperconjugant interactions of pyridine rings associated to $\pi(\mathrm{N} 8-\mathrm{C} 10) \rightarrow \pi^{*}(\mathrm{C} 5-\mathrm{C} 6)$ and $\pi(\mathrm{N} 25-\mathrm{C} 27) \rightarrow \pi^{*}(\mathrm{C} 22-\mathrm{C} 23)$ interactions is in the order of $11 \mathrm{kcal} \mathrm{mol}^{-1}$. Finally, we can conclude that the NBO analysis confirms that the hydrogen bonding in the $2 \mathrm{~A} 5 \mathrm{PCoCl}_{4}$ compound leads to his crystal structure.

\subsection{Frontier molecular orbital analysis}

In our study, we generally not focus on a comparison between the MOs but instead just take the MOs as a set of orbitals for the whole molecule. So we will always focus simply on the electrons which are the most important. Indeed, there are the Highest Occupied Molecular Orbital (HOMO) which is the highest energy MO that has any electrons in it and the lowest un-Occupied Molecular Orbital (LUMO) is the next highest energy orbital, it will be empty and is the lowest energy place to put or excite an electron. These orbitals play an important role in chemical stability of the molecular edifice. The difference in energy between the HOMO and LUMO is called the HOMO-LUMO gap. This latter between these two frontier orbitals can be used to predict the strength and stability of transition metal complexes and can tell us about what wavelengths the compound can absorb. A high gap indicates a high stability of the molecule. Low gap energy is criterion of high reactivity. The picture 
representations of the (HOMO, HOMO-1 and LUMO, LUMO+1) and the contribution of the organic and inorganic units to these orbitals of $2 \mathrm{~A} 5 \mathrm{PCoCl}_{4}$ are mapped in Fig. 7 and the results of this survey are gathered in Table S4. The red and the green colors of the MO plot show the positive and negative phase, respectively. It is observed that the highest occupied orbitals are localized on the organic cation but the lowest unoccupied orbital's is located on the anionic part. The calculated energy values of HOMO and LUMO are around $-5.37 \mathrm{eV}$ and $-2.49 \mathrm{eV}$ respectively. The energy gap between the HOMO and LUMO is $+2.88 \mathrm{eV}$. This value agree very well with the corresponding energy gap reported earlier of others organic tetrachlorocobaltate(II) compounds [48-49].

\subsection{Vibrational IR spectra and assignments}

For the determination of vibrational characteristics of $2 \mathrm{~A}^{2} \mathrm{PCoCl}_{4}$ we add a vibrational study using infrared spectroscopy at room temperture. The experimental infrared wavenumber compared to the calculated from DFT method assigned by VEDA4 program [27] and GaussView software [26] were listed in Table S5 along with a tentative assignement of the observed bands. In this table, we have presented the scaled and the unscaled calculated harmonic vibrational frequencies, infrared intensity and detailed PED assignement. In our study, wavenumbres are in the ranges from 4000 to $400 \mathrm{~cm}^{-1}$. The experimental IR spectrum according the calculated is illustrated in Fig. 8. By reference to the results of the assignment and to the bibliographic study [50-54] we have ascribed the organic cation to the set of bands that appeared in IR spectrum.

\subsubsection{Vibrational modes of the anion}

The compound crystallizes in the orthorhombic system $\mathrm{P} 2{ }_{1} / \mathrm{c}$, the elemental cell contains four form units occupying four crystallographically equivalent sites. The $\left[\mathrm{CoCl}_{4}\right]^{2-}$ anion has $\mathrm{C}_{1}$ site symmetry. Work perform on infrared absorption spectroscopy allowed us on one hand to determine the vibrational characteristics of the atomic groups of compound, and the enumration of the modes of vibration of the $\left[\mathrm{CoCl}_{4}\right]^{2-}$ groups on the other hand. The tetrahedral anion $\left[\mathrm{CoCl}_{4}\right]^{2-}$ contains 5 atoms so it has $(5 \times 3)-6=9$ modes of vibration. The six subtracted modes correspond to the three rotations ( $\mathrm{Rx}, \mathrm{Ry}, \mathrm{Rz})$ and to the three translations (Tx, Ty, Tz) of the whole ion. Based on the correlation method we find that the $\mathrm{CoCl}_{4}{ }^{2-}$ anion has $9\left(\mathrm{~A}_{\mathrm{u}}+\mathrm{B}_{\mathrm{u}}+\mathrm{A}_{\mathrm{g}}+\mathrm{B}_{\mathrm{g}}\right)$ active modes in IR and $9\left(\mathrm{~A}_{\mathrm{u}}+\mathrm{B}_{\mathrm{u}}+\mathrm{A}_{\mathrm{g}}+\mathrm{B}_{\mathrm{g}}\right)$ modes active in Raman, they are shared in four fundamental modes $v_{1}, v_{2}, v_{3}$ et $v_{4}$. We have distinguished the four fundamental modes $\left(v_{1}, v_{2}, v_{3}\right.$ and $\left.v_{4}\right)$ of the $\left[\mathrm{CoCl}_{4}\right]^{2-}$ anion in the wave number region 
from 50 to $300 \mathrm{~cm}^{-1}$. In fact, symmetric $\left(v_{2}\right)$ and asymmetric $\left(v_{4}\right)$ stretching vibrations are attributed to the Raman peaks observed at 107 and $132 \mathrm{~cm}^{-1}$, respectively. The same stretching vibration is pedicted at 1111 and $137 \mathrm{~cm}^{-1}$ by DFT method. Their corresponding bending vibration modes are respectively 220 and $276 \mathrm{~cm}^{-1}$. This mode is theorecally calculated between 237 and $268 \mathrm{~cm}^{-1}$ by DFT method.

\subsubsection{Vibrational modes of the cation}

Based on the work reported above we have estimated the vibration domain of the organic group which is located between 541 and $3324 \mathrm{~cm}^{-1}$ (Fig. 8) and shows the bands corresponding to the characteristic vibrational modes of $2 \mathrm{~A} 5 \mathrm{PCoCl}_{4}$ which compared with those of similar salts.

In fact, the intense bands in 3324 and $3211 \mathrm{~cm}^{-1}$ correspond to the valence vibrations of the groups $\left(-\mathrm{NH}^{+}\right),\left(-\mathrm{NH}_{2}\right)$ and $(\mathrm{C}-\mathrm{H})$, so the broadening of these bands is due to the establishment of the hydrogen bonds, which effect the lowering of the frequencies of these groups. The same vibrations are calculated between 3231 and $3697 \mathrm{~cm}^{-1}$ by DFT level. The bands between 1674 and $1588 \mathrm{~cm}^{-1}$ are attributed to the valence vibrations $v(\mathrm{C}=\mathrm{C})$ of the aromatic ring and the symmetric and asymmetric vibrations of the $\left(-\mathrm{NH}^{+}\right),\left(-\mathrm{NH}_{2}\right)$ and $\left(-\mathrm{CH}_{3}\right)$ groups. The corresponding bands are calculated at range 1593 and $1708 \mathrm{~cm}^{-1}$. In the range $1355-1155 \mathrm{~cm}^{-1}$, the bands attributed to the valence vibrations of the group $v\left(\mathrm{C}_{\text {aryl }}-\mathrm{C}\right)$ and $v(\mathrm{C}-\mathrm{N})$ appear, nearlly at the calculated one among 1155 and $1355 \mathrm{~cm}^{-1}$.

Finally, the observed weak band which is located towards $996 \mathrm{~cm}^{-1}$ and $514 \mathrm{~cm}^{-1}$, and between 499 and $1017 \mathrm{~cm}^{-1}$ in calculated IR spectrum, are attribuated to the $(\mathrm{C}-\mathrm{H})$ group of the pyridine ring its off-plane deformation.

\subsection{Molecular Electrostatic Potentials (MEP)}

The Molecular Electrostatic potentials (MEP) play a key role in the characterization of interaction energy between the electric charge produced by the electrons and the nuclei of the molecule. MEP is one of the best suitable tools for prediction of the presence of inter- and intramolecular interactions of the studied compounds. It is a useful descriptor to determine the active sites of electrophilic and nucleophilic attacks over the molecule for the study of biological recognition process as well as hydrogen-bonding interactions [55]. The MEP surface of $2 \mathrm{~A}_{5} \mathrm{PCoCl}_{4}$ was made by using the software Gauss view (Fig. 9). The mapping represent the donor atoms in blue regions with positive potential, is the most positive 
electrostatic potential (nucleophilic site) and it is localized hydrogen atoms and the acceptor atoms with negative potential in red regions represents the most electronegative potential (electrophilic sites) and it is mainly localized over anionic group (red, chlorine atoms), whereas the green or yellow colors indicates the neutral region [56]. This graph shows that the electrophilic sites are located around the hydrogen atoms, whereas the nucleophilic sites are located around the chlorine atoms. MEP surface represents a proof of the formation of the hydrogen bond [57]; it is defined as being a donor acceptor interaction. It proves that the electrostatic potential of the donor becomes less negative as the acceptor becomes more negative.

\subsection{Thermal behavior}

To understand the behavior of the title compound, thermal analysis DTA/TG (Fig. 10) of $2 \mathrm{~A} \mathrm{PCoCl}_{4}$ carried out shows that our compound undergoes a phase transition at $327 \mathrm{~K}$. Then a series of endothermic peaks are observed on the DTA curve accompanied by a weight loss on the TG curve which can be attributed to the pyrolysis of the organic molecule. Finally, an endothermic peak without loss of mass appears at $521 \mathrm{~K}$ which can correspond to melting. This phenomenon is further confirmed by the heating of our compound on a Kofler bench which makes it possible to estimate the melting temperature of a material, this temperature $517 \mathrm{~K}$ is close to that found on the DTA curve. After that the remaining product undergoes a total combustion which leads to a volatile gas and a black carbonaceous residue.

\section{Conclusion}

The present study reports on the synthesis and subsequent characterization of a new organic tetrachlorocobaltate(II), $2 \mathrm{~A} 5 \mathrm{PCoCl}_{4}$. This novel $\mathrm{Co}(\mathrm{II})$ complex has been successfully synthesized at room temperature by slow evaporation solution growth technique in the monoclinic system with the $\mathrm{P} 2{ }_{1} / \mathrm{c}$ space group. The structural level the atomic arrangement can be described by the alternation of organic and inorganic layers. The anionic arrangement is built up by tetrahedral of $\left[\mathrm{CoCl}_{4}\right]^{2-}$ arranged in sandwich between the organic layers, interconnected by means of the ionic $\mathrm{N}-\mathrm{H}$... Cl hydrogen bonds. The crystal packing is stabilized by intermolecular H-bonding and $\pi-\pi$ stacking interactions which were confirmed by topological AIM approaches. Moreover, the Hirshfeld surface analysis reveals the percentage of intermolecular contacts and highlights the non-covalent interactions in $2 \mathrm{~A} 5 \mathrm{PCoCl}_{4}$. The TG/DTA thermal analysis was performed to establish the thermal stability of the crystal. The vibrational wavenumbers of the fundamental modes of $2 \mathrm{~A}^{2} \mathrm{PCoCl}_{4}$ have been 
precisely assigned, analyzed, and the theoretical results were compared with the experimental values. NBO analysis explained the stability of the synthesized compound. HOMO-LUMO, energy gap, molecular hardness, ionization energy, electron affinity were predicted by using DFT level.

\section{Acknowledgements}

This work was supported by the Ministry of Higher Education and Scientific Research of Tunisia.

\section{References}

[1] C. R. Kagan, D. B. Mitzi, C. D. Dimitrakopoulos, Organic-Inorganic Hybrid Materials as Semiconducting Channels in Thin-Film Field-Effect Transistors, Sci. 286 (1999) 945-947.

[2] J. L. Knutson, J. D. Martin, D. B. Mitzi, Tuning the Band Gap in Hybrid Tin Iodide Perovskite Semiconductors Using Structural Templating, Inorg. Chem. 44 (2005) 4699-4705.

[3] T. Sekine, T. Okuno, K. Awaga, Intermolecular Arrangements of p-Substituted Aniliniums in the Interlayer of Cupric Chloride, Mol. Cryst. Liq. Cryst. 279 (1996) 65-12.

[4] C. Aruta, F. Licci, A. Zappettini, F. Bolzoni, F. Rastelli, P. Ferro, T. Besagni, Growth and optical, magnetic and transport properties of $\left(\mathrm{C}_{4} \mathrm{H}_{9} \mathrm{NH}_{3}\right)_{2} \mathrm{MCl}_{4}$ organic-inorganic hybrid films (M=Cu, Sn), Appl. Phys. A 81 (2005) 963-986.

[5] J-C Chang, W-Y Ho, I-W Sun, Y-K Chou, H-H Hsieh, T-Y Wu, Synthesis and proprieties of new tetrachlorocobaltate(II) and tetrachloromanganate(II) anion salts with dicationic counterions, Polyhedron 30 (2011) 497-507.

[6] K. Chondroudis, D. B. Mitzi, Electroluminescence from an Organic-Inorganic Perovskite Incorporating a Quaterthiophene Dye within Lead Halide Perovskite Layers, J. Chem. Mater. 11 (1999) 3028-3030.

[7] Y. Tominaga, H. Ohno, Electrochim, Lithium ion conduction in linear- and networktype polymers of PEO/sulfonamide salt hybrid, Acta Crystallogr. E45. (2000) 3081-3086.

[8] V. Di Noto, M. Fauri, M. Vittadello, S. Lavina, S. Biscazzo, Zeolitic inorganicorganic polymer electrolytes: Synthesis, characterization and ionic conductivity of a material based on oligo(ethylene glycol) $600,\left(\mathrm{CH}_{3}\right)_{2} \mathrm{SnCl}_{2}$ and $\mathrm{K}_{4} \mathrm{Fe}(\mathrm{CN})_{6}$, Electrochim. Acta 46 (2001) 1587-1594.

[9] C. Sanchez, P. Belleville, M. Popalld, L. Nicole. Chem, Applications of advanced hybrid organic-inorganic nanomaterials: from laboratory to market, Soc. Rev. 40 (2011) 696753. 
[10] R. Pardo, M. Zayat, D. Levy. Chem, Photochromic organic-inorganic hybrid materials, Soc. Rev. 40 (2011) 672-687.

[11] B. B. Koleva, T. Kolev, T. Tsanev, H. Mayer-Figge, R. W. Seidel, and W. S. Sheldrick,, Spectroscopic and structural elucidation of 3,4-diaminopyridine and its hydrogentartarate salt: Crystal structure of 3,4-diaminopyridinium hydrogentartarate dihydrate, J. Mol. Struct. 881 (2008) 146-155.

[12] N. Moutia, A. Oueslati, M. Ben Gzaiel, K. Khirouni, Crystal structure and AC conductivity mechanism of $\left[\mathrm{N}\left(\mathrm{C}_{3} \mathrm{H}_{7}\right)_{4}\right] 2 \mathrm{CoCl}_{4}$ compound, Physica E83 (2016) 88-94.

[13] M. Essid, T. Roisnel, M. Rzaigui, H. Marouani, Synthesis, crystal structure, and characterization of a new non-centrosymmetric organic-inorganic hybrid material: $\left[\mathrm{C}_{6} \mathrm{H}_{16} \mathrm{~N}_{2}\right]_{2}\left(\mathrm{BiBr}_{6}\right) \mathrm{NO}_{3}$, Monatsh Chem. 146 (2015) 1959-1965.

[14] M. A. Kandhaswamy, V. Srinivasan, Synthesis and characterization of tetraethylammonium tetrachlorocobaltate crystals, Bull. Mater. Sci. 25 (2002) 41-45.

[15] W.Q. Chen, M.H. Feng, D.D. Zhou, Y.Q. Peng, S. Han, X.P. Liu, L.M. Yang, J.R. Zhou, C.L. Ni, Two Tetrachlorocobaltate(II) Salts With Substituted Benzyl Triphenylphosphonium: Syntheses, Crystal Structures, Weak Interactions, and Magnetic Properties, Synth. React. Inorg. M. 42 (2012) 811-817.

[16] F. Issaoui, Y. Baklouti, E. Dhahri, F. Zouari;-M. A. Valente, Crystal Structure and Magnetic Property Studies of a Novel Hybrid Compound $\left(\mathrm{C}_{6} \mathrm{H}_{16} \mathrm{~N}_{2}\right) \mathrm{CoCl}_{4}$, Supercond. Nov. Magn. 28 (2015) 2621-2626.

[17] E. Styczeń, Z. Warnke, D. Wyrzykowski, ynthesis and thermal analysis of tetraethylammonium bromochlorocobaltates(II) $\left[\mathrm{Et}_{4} \mathrm{~N}_{2}\left[\mathrm{CoBr}_{n} \mathrm{Cl}_{4-n}\right]\right.$, Thermochim. Acta 454 (2007) 84-89

[18] Bruker, APEX2, SAINT and SADABS, Bruker AXS Inc., Madison, Wisconsin, USA, (2006).

[19] L. J. Farrugia. WinGX and ORTEP for Windows: an update. J. Appl. Cryst. 45 (2012). 849-854.

[20] G. M. Sheldrick. Crystal structure refinement with SHELXL. Acta Crystallogr. C71 (2015) 3-8.

[21] K. Brandenburg and H. Putz, DIAMOND Crystal Impact GbR, Bonn, Germany, (1999).

[22] S.K. Wolff, S.D.J. Greenwood, J.J. McKinnon, D. Jayatilaka, M.A. Spackman, Crystal Explorer 3.1, University of Western Australia, Perth, Australia, 2013. 
[23] M. J. Frisch, et al., GAUSSIAN 09, Revision A.02, Gaussian, Inc., Wallingford, CT, 2009.

[24] A.D. Becke, Becke's three parameter hybrid method using the LYP correlation functional, J. Chem. Phys. 98 (1993) 5648-5652.

[25] C. Lee, W. Yang, R. G. Parr, Development of the Colle-Salvetticonelation energy formula into a functional of the electron density, Phys. Rev. 37 (1988) 785-789.

[26] R Dennington, T. Keith, J. Millam, GaussView, Version 5, Semichem. Inc, Shawnee Mission, KS, 2009.

[27] M.H. Jamróz, Vibrational Energy Distribution Analysis, vol. 4, VEDA, Poland, 2004. Computer Program.

[28] ED. Glendening, JK. Badenhoop, AE. Reed, J.E. Carpenter, F. Weinhold, NBO 3.1, Theoretical Chemistry Institue, University of Wisconsin, Madison, WI Oxford, (1996), ISBN $0198558651, \mathrm{p}, 1990$.

[29] T. Lu, F. Chen, Multiwfn: a multifunctional Wavefunction analyzer, J. Compt. Chem. 33 (2012) 580-592.

[30] R.F.W. Bader, Atoms in Molecules, A Quantum Theory, Oxford University Press, Oxford, (1990), ISBN 0198558651.

[31] W. Humphrey, A. Dalke, K. Schulten, J. Mol. Graph. 14 (1996) 27-38.

[32] L. Yang, D. R. Powell, R. P. Houser, Structural variation in copper(I) complexes with pyridylmethylamide ligands: structural analysis with a new four-coordinate geometry index, $\tau_{4}$, Dalton Trans. 9 (2007) 955-964.

[33] W. H. Baur, Acta Crystallogr. B30 (1974) 1191-1195.

[34] T. Ferchichi, B. Trojett, H. Dhaouadi, H. Marouani, 1,4,8,11Tetraazoniacyclotetradecane tetrachloridocobaltate(II) dichloride, Acta Crystallogr. E66 (2010) m869-m870.

[35] M. Hemamalini, H-K Fun, 2-Amino-5-methylpyridinium 2-carboxyacetate, Acta Crystallogr. E66 (2010) o1480-o1481

[36] H. Dhaouadi, H. Marouani, M. Rzaigui, Crystal structure of $o$-aminopyridinium dihydrogenmonophosphate, $\left(\mathrm{NH}_{2} \mathrm{C}_{5} \mathrm{H}_{4} \mathrm{NH}\right)\left[\mathrm{H}_{2} \mathrm{PO}_{4}\right]$, Z. Kristallogr. NCS 220 (2005) 433-434.

[37] C. Jelsch, K. Ejsmont, L. Huder, The enrichment ratio of atomic contacts in crystals, an indicator derived from the Hirshfeld surface analysis, IUCrJ 1 (2014) 119-128; 
[38] A. Guesmi, T. Roisnel, H. Marouani, Featuring non-covalent interactions in mxylylenediaminium bis(perchlorate) monohydrate: Synthesis, characterization and Hirshfeld surface analysis, J. Mol. Struct. 1194 (2019) 66-72.

[39] U. Koch, P. L. A. Popelier, Characterization of C-H-O Hydrogen Bonds on the Basis of the Charge Density, J. Phys. Chem. 99 (1995) 9747-9754.

[40] I. Rozas, I. Alkorta, J. Elguero, Behavior of Ylides Containing N, O, and C Atoms as Hydrogen Bond Acceptors, J. Am. Chem. Soc. 122 (2000) 11154-11161.

[41] E. Espinosa, E. Molins, C. Lecomte, Hydrogen bond strengths revealed by topological analyses of experimentally observed electron densities, Chem. Phys. Lett. 285 (1998) 170173.

[42] E. R. Johnson, Sh. Keinan, P. Mori-Sanchez, J. Contreras-Garcia, A. J. Cohen, W. Yang, Revealing Noncovalent Interactions, J. Am. Chem. Soc. 132 (2010) 6498-6506.

[43] E.R. Johnson, S. Keinan, P. Mori-Sánchez, J. Contreras-García, A. J. Cohen, W. Yang, Revealing Noncovalent Interactions, J. Am. Chem. Soc. 132 (2010) 6498-6506.

[44] N.S. Venkataramanan, Cooperativity of intermolecular hydrogen bonds in microsolvated DMSO and DMF clusters: a DFT and AIM and NCI analysis, J. Mol. Model. 22 (2016) 151-163.

[45] N.S. Venkataramanan, A. Suvitha, Y. Kawazoe, Intermolecular interaction in nucleobases and dimethyl sulfoxide/water molecules: A DFT, NBO, AIM and NCI analysis J. Mol. Graph. Model. 78 (2017) 48-60.

[43] A. E. Reed, F. Weinhold, L. A. Curtiss, D. J. Pochatko, Natural bond orbital analysis of molecular interactions: Theoretical studies of binary complexes of $\mathrm{HF}, \mathrm{H}_{20}, \mathrm{NH}_{3}, \mathrm{~N}_{2}, \mathrm{O}_{2}$, $\mathrm{F}_{2}, \mathrm{CO}$, and $\mathrm{CO}_{2}$ with $\mathrm{HF} \mathrm{H}_{20}$ and $\mathrm{NH}_{3}$, J. Chem. Phys. 84 (1986) 5687.

[47] M. Kurt, P. Babu, N. Sundaraganesan, M. Karabacak, Molecular structure, vibrational, UV and NBO analysis of 4-chloro-7-nitrobenzofurazan by DFT calculations, Spectrochim. Acta A Mol. Biomol. Spectrosc. 79 (2011) 1162-1170.

[48] M. Said, H. Boughzala, Synthesis, crystal structure, vibrational study, optical properties and thermal behavior of a new hybrid material bis(3-amino-4-phenyl-1Hpyrazolium) tetrachloridocobaltate, (II) monohydrate, J. Mol. Struct. 1203 (2020) 127413.

[49] N.M. Juibari, A. Abbasi, M. Najafi, S Geranmayeh, Synthesis and characterization of a novel nanosized $\left\{\left[\mathrm{H}_{2} \mathrm{tpphz}\right]\left[\mathrm{CoCl}_{4}\right]\right\}_{\mathrm{n}}$ compound: Combined crystallographic, topologic and DFT-calculation approach, C. R. Chimie 18 (2015) 662-667. 
[50] O. Noureddine, S. Gatfaoui, S. A. Brandán, H. Marouani, N. Issaoui, Structural, docking and spectroscopic studies of a new piperazine derivative, 1-Phenylpiperazine-1,4diium-bis (hydrogen sulfate), J. Mol. Struct. 1202 (2020) 1-23.

[51] S. Gatfaoui, N. Issaoui, A. Mezni, F. Bardak, T. Roisnel, A. Atac, H.Marouani, Synthesis, structural and spectroscopic features, and investigation of bioactive nature of a novel organic-inorganic hybrid material 1H-1,2,4-triazole-4-ium trioxonitrate, J. Mol. Struct. 1150 (2017) 242-257.

[52] C.B. M'leh, S.A. Brandán, N. Issaoui, T. Roisnel, H. Marouani, Synthesis, molecular structure, vibrational and theoretical studies of a new non-centrosymmetric organic sulphate with promising NLO properties, J. Mol. Struct. 1171 (2018) 771-785.

[53] S. Trabelsi, N. Issaoui, S.A. Brandán, F. Bardak, T. Roisnel, A. Atac, H. Marouani, Synthesis and physic-chemical properties of a novel chromate compound with potential biological applications, bis(2-phenylethylammonium) chromate(VI), J. Mol. Struct. 1185 (2019) 168-182.

[54] S. Gatfaoui, N. Issaoui, S.A. Brandán, T. Roisnel, H. Marouani, Synthesis and characterization of p-xylylenediaminium bis(nitrate). Effects of the coordination modes of nitrate groups on their structural and vibrational properties, J. Mol. Struct. 1151 (2018) 152168.

[55] A. Volkov, P. Coppens. Calculation of electrostatic interaction energies in molecular dimers from atomic multipole moments obtained by different methods of electron density partitioning, J. Comput. Chem. 25 (2004) 921-934.

[56] A.E. Reed, F. Weinhold, Natural localized molecular orbitals, J. Chem. Phys. 83 (1985) 1736-1740.

[57] N. Mohan, C.H. Suresh, A molecular electrostatic potential analysis of hydrogen, halogen and dihydrogen bonds, J. Phys. Chem. 118 (2014) 1697-1705. 
- A new $\mathrm{Co}(\mathrm{II})$ complex compound, $2 \mathrm{~A} 5 \mathrm{PCoCl}_{4}$, was prepared at room temperature.

- The atomic arrangement of the $2 \mathrm{~A}^{2} \mathrm{PCoCl}_{4}$ shows three-dimensional network.

- The optimized geometry and vibrational wavenumbers are computed using DFT(B3LYP/LANL2DZ) method.

- $2 \mathrm{~A} 5 \mathrm{PCoCl}_{4}$ was characterized by X-ray, FT-IR and DTA/TG analyses.

- The intermolecular interactions were analyzed by Hirshfeld surfaces, AIM, NBO, RDG and MEP. 


\section{Figure captions}

Fig. 1. ORTEP of $2 \mathrm{~A}^{2} \mathrm{PCoCl}_{4}$ with atoms-labeling scheme. Displacement ellipsoids are drawn at the $30 \%$ probability level. Hydrogen atoms are represented as small spheres (a) and the optimized molecular structure (b).

Fig. 2. Projection along the $\overrightarrow{\boldsymbol{a}}$ axis of atomic arrangement of $2 \mathrm{~A} 5 \mathrm{PCoCl}_{4}$ (a). Projection along the $\vec{c}$ axis showing the interactions between inorganic and ammonium groups in $2 \mathrm{~A} 5 \mathrm{PCoCl}_{4}$ (b). Hydrogen bond motifs observed in $2 \mathrm{~A}^{2} \mathrm{PCoCl}_{4}$ (c).

Fig .3. Hirshfeld surfaces mapped with $\mathrm{d}_{\text {norm }}(-0.395$ - 1.151) (a) (dotted lines "red" represent hydrogen bonds), shape index $(-1-1)(b)$ and curvedness $(-4-4)$ (c) for $2 \mathrm{~A}^{2} \mathrm{PCoCl}_{4}$.

Fig. 4. Fingerprint plots of the full and the significant intercontacts and percentage of various intermolecular contacts contributed to the Hirshfeld surface in $2 \mathrm{~A}^{2} \mathrm{PCoCl}_{4}$ compound.

Fig. 5. AIM molecular graphic showing the different critical points of $2 \mathrm{~A} 5 \mathrm{PCoCl}_{4}(\mathrm{BCP}$ : small red sphere, RCP: small yellow sphere, bond paths: yellow lines).

Fig. 6. Representation of different types of interactions in $2 \mathrm{~A} 5 \mathrm{PCoCl}_{4}$ compound (a). The map of Reduced Density Gradient (RDG) defines the interaction limits for $2 \mathrm{~A} 5 \mathrm{PCoCl}_{4}(\mathrm{~b})$.

Fig. 7. The frontier molecular orbitals of $2 \mathrm{~A} 5 \mathrm{PCoCl}_{4}$ computed with TD-DFT (B3LYP)/6$311++\mathrm{G}(\mathrm{d}, \mathrm{p})$ method.

Fig. 8. Theoretical (blue) and experimental (red) IR spectra of $2 \mathrm{~A} 5 \mathrm{PCoCl}_{4}$.

Fig. 9. Molecular Electrostatic Potentials (MEP) surface mapped of $2 \mathrm{~A} 5 \mathrm{PCoCl}_{4}$.

Fig. 10. DTA and TG curves of $2 \mathrm{~A} 5 \mathrm{PCoCl}_{4}$. 
(a)

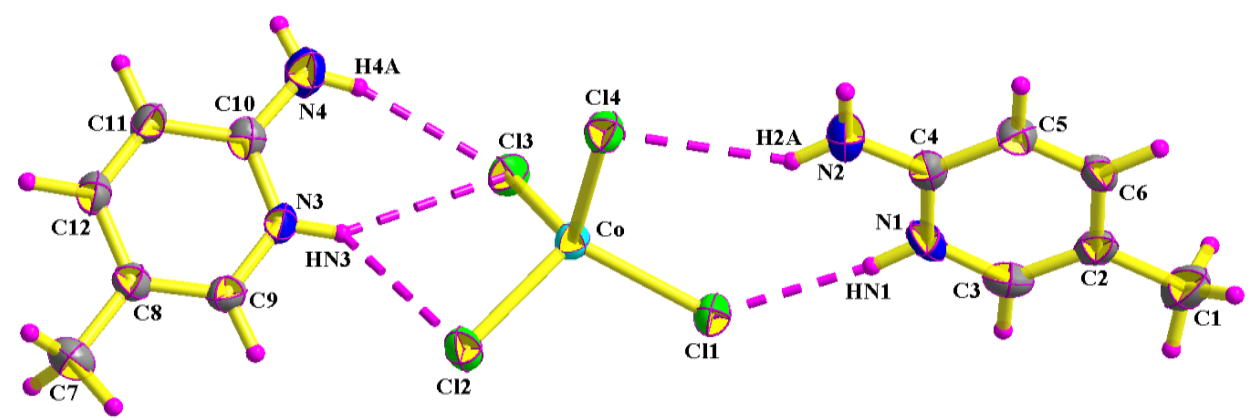

(b)

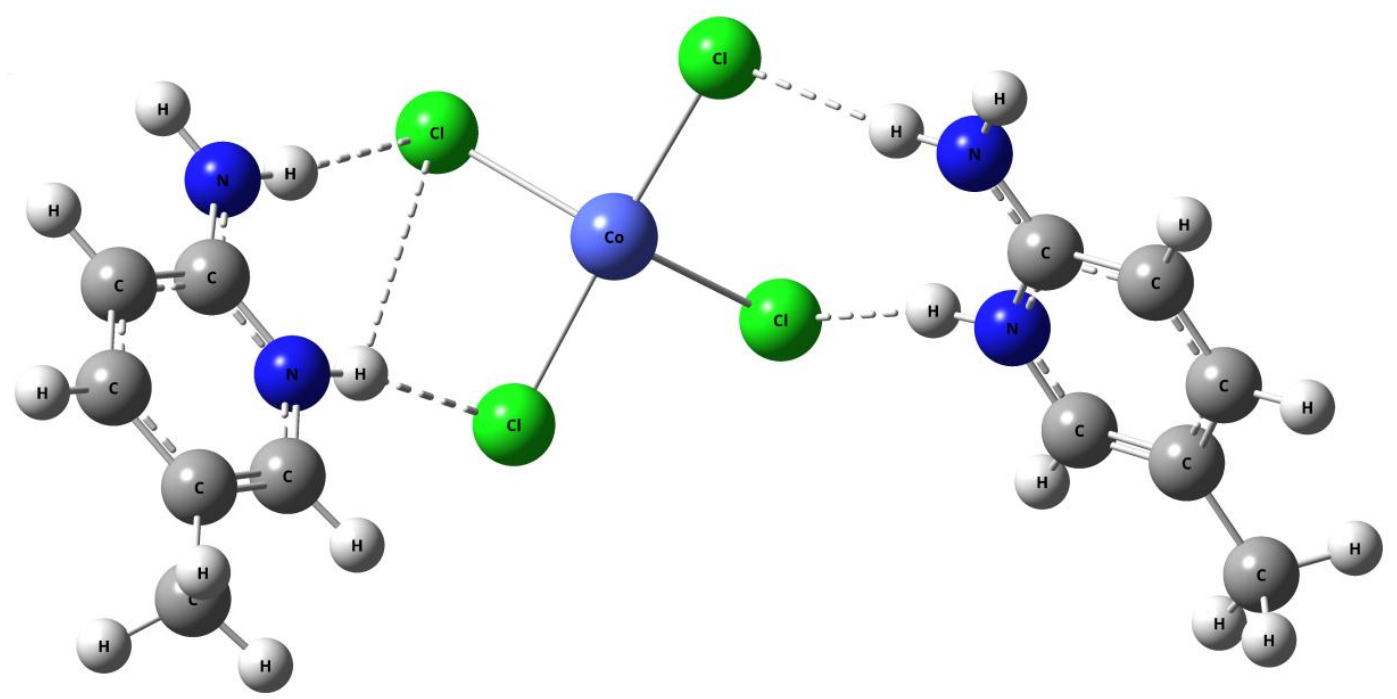

Fig. 1. ORTEP of $2 \mathrm{~A} 5 \mathrm{PCoCl}_{4}$ with atoms-labeling scheme. Displacement ellipsoids are drawn at the $30 \%$ probability level. Hydrogen atoms are represented as small spheres (a) and the optimized molecular structure (b). . 
(a)

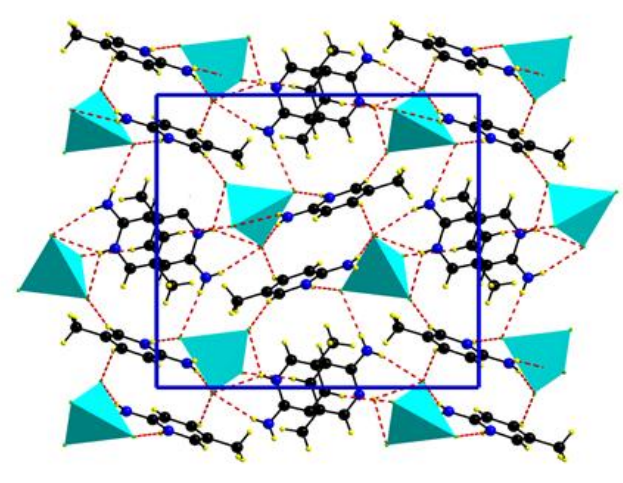

(b)

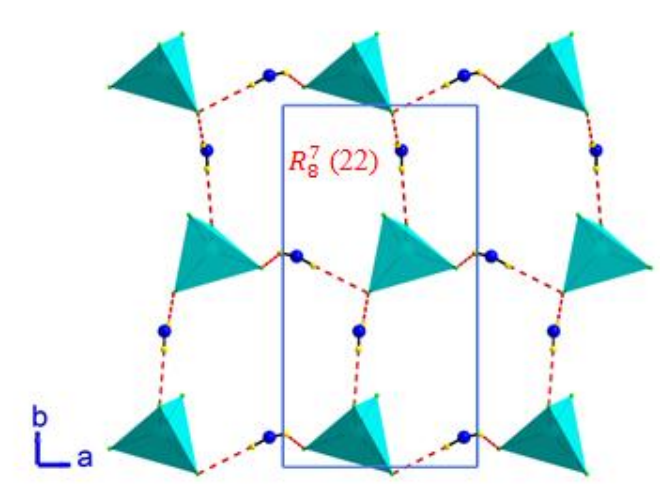

(c)

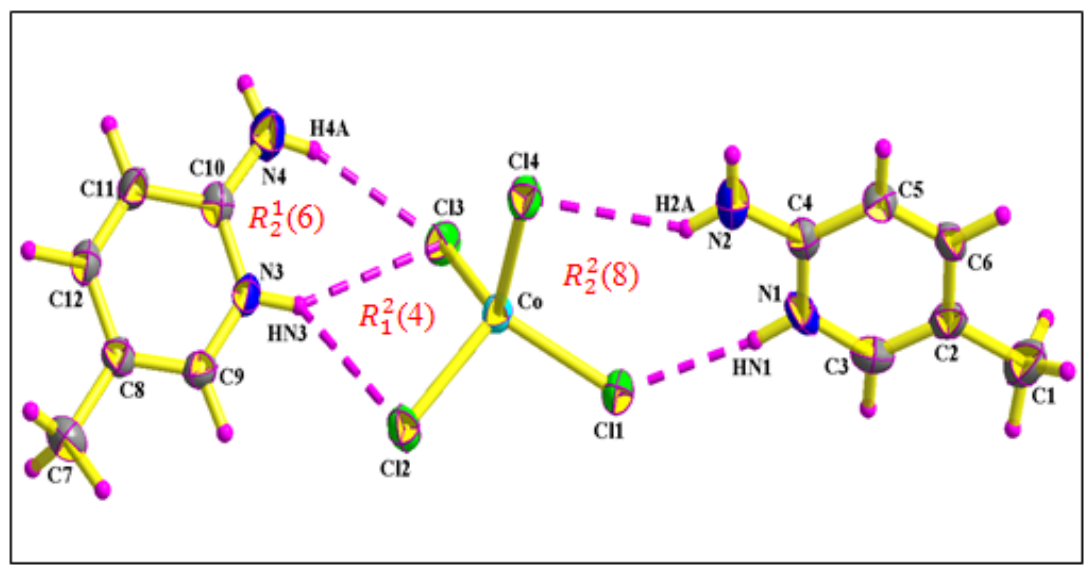

Fig. 2. Projection along the $\overrightarrow{\boldsymbol{a}}$ axis of atomic arrangement of $2 \mathrm{~A} 5 \mathrm{PCoCl}_{4}$ (a). Projection along the $\vec{c}$ axis showing the interactions between inorganic and ammonium groups in $2 \mathrm{~A}_{5} \mathrm{PCoCl}_{4}$ (b). Hydrogen bond motifs observed in $2 \mathrm{~A}^{2} \mathrm{PCoCl}_{4}$ (c). 
(a)

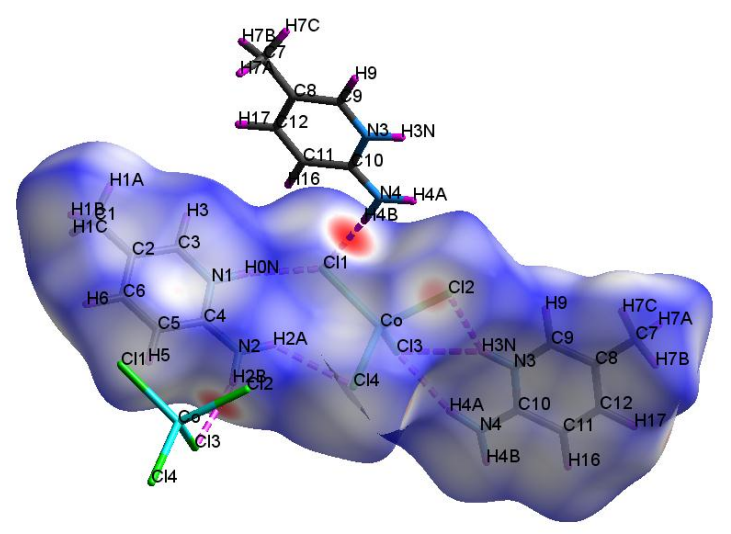

(b)

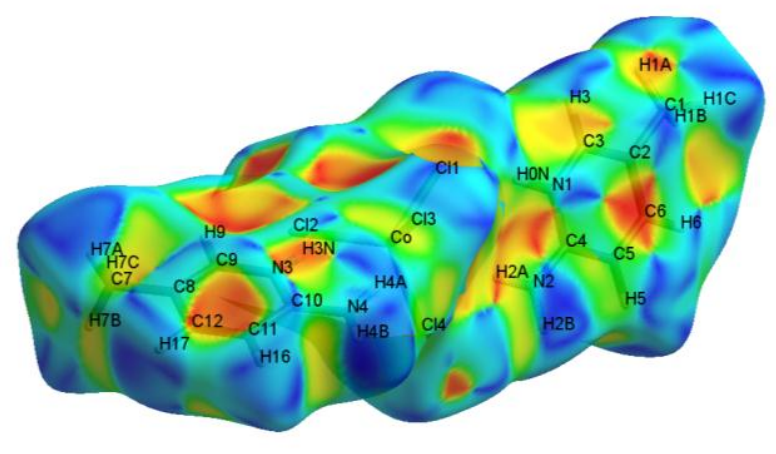

(c)

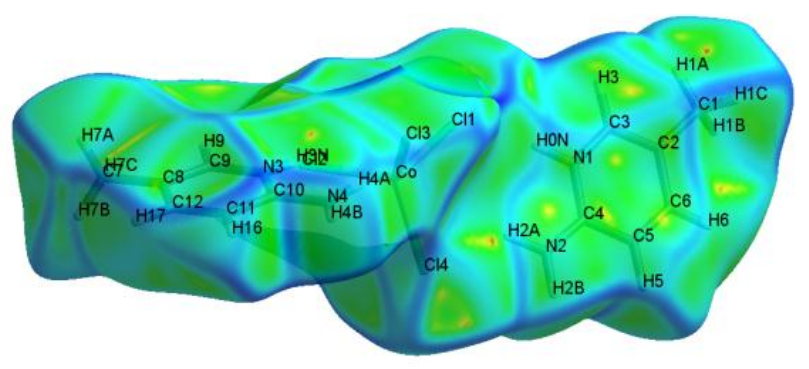

Fig. 3. Hirshfeld surfaces mapped with $\mathrm{d}_{\text {norm }}(-0.395$ - 1.151) (a) (dotted lines "red" represent hydrogen bonds), shape index (-1 - 1) (b) and curvedness $(-4-4)$ (c) for $2 \mathrm{~A}^{2} \mathrm{PCoCl}_{4}$. 

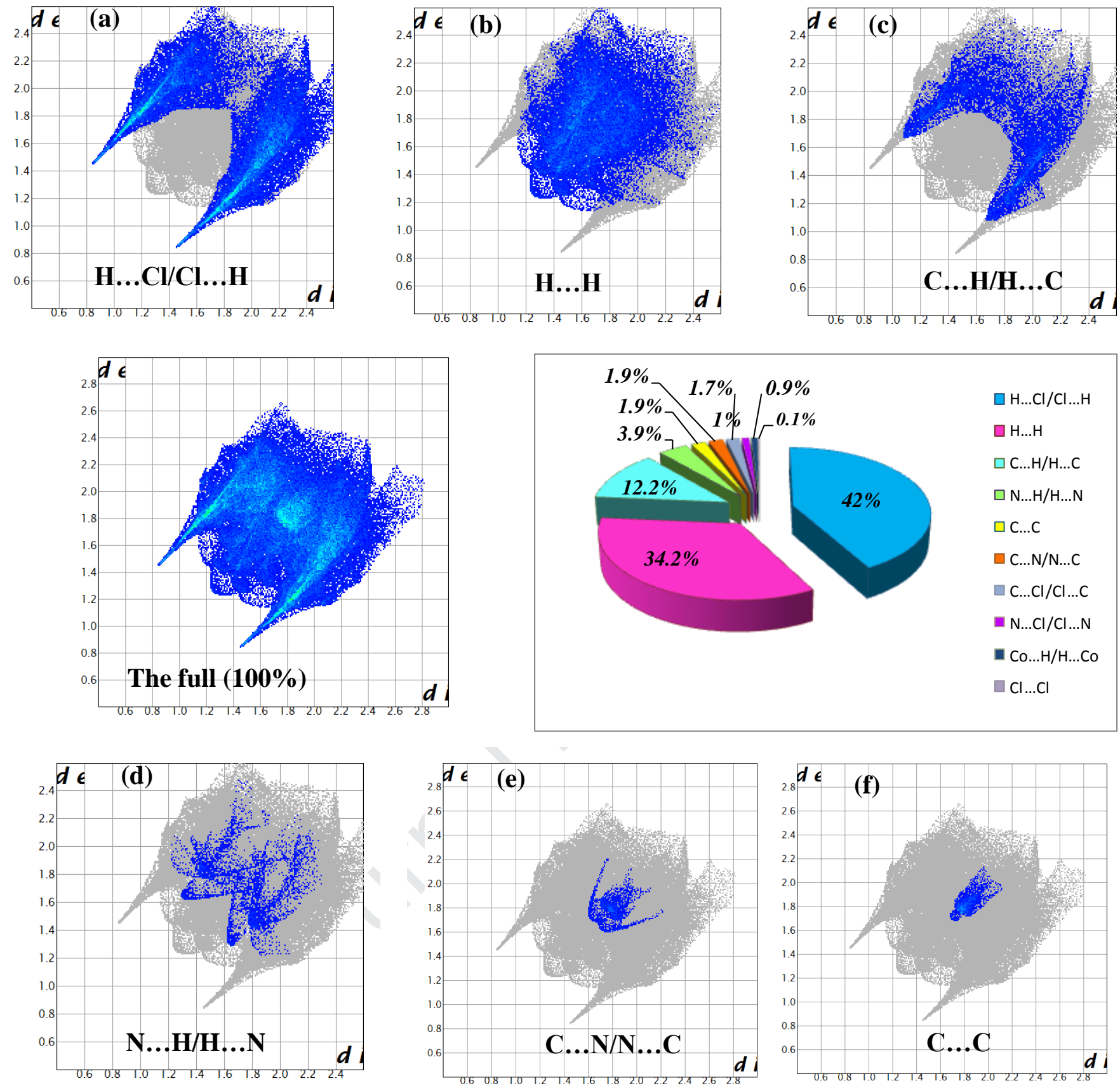

Fig. 4. Fingerprint plots of the full and the significant intercontacts and percentage of various intermolecular contacts contributed to the Hirshfeld surface in $2 \mathrm{~A}^{2} \mathrm{PCoCl}_{4}$ compound. 


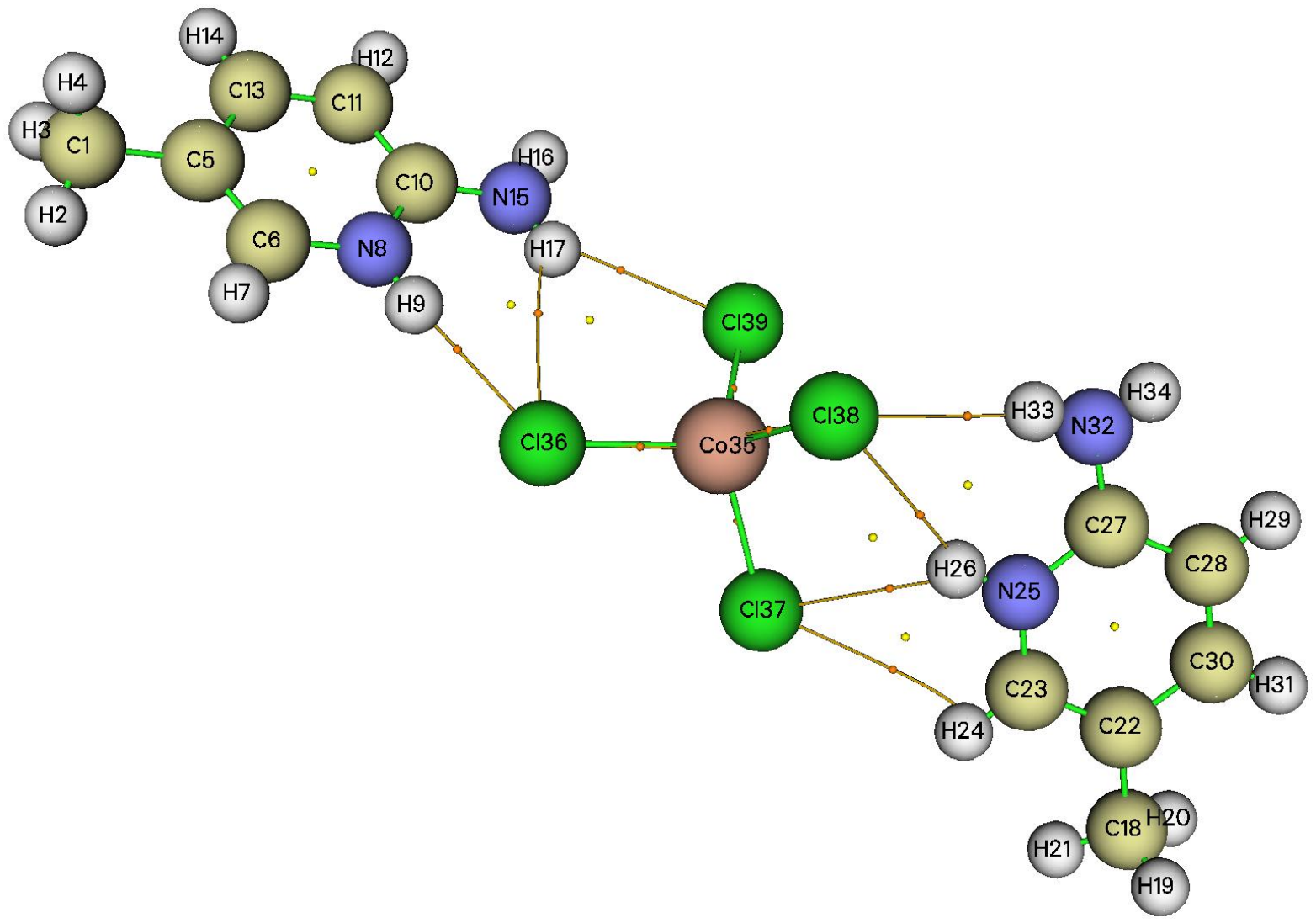

Fig. 5. AIM molecular graphic showing the different critical points of $2 \mathrm{~A} 5 \mathrm{PCoCl}_{4}(\mathrm{BCP}$ : small red sphere, RCP: small yellow sphere, bond paths: yellow lines). 
(a)

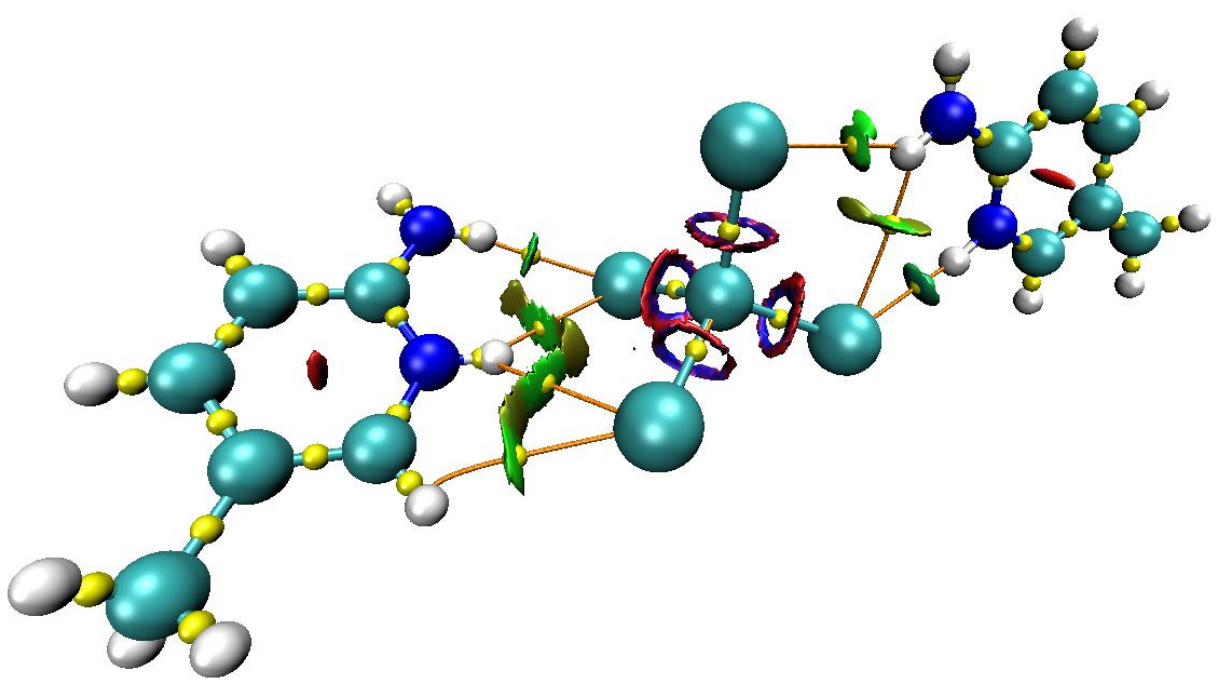

(b)

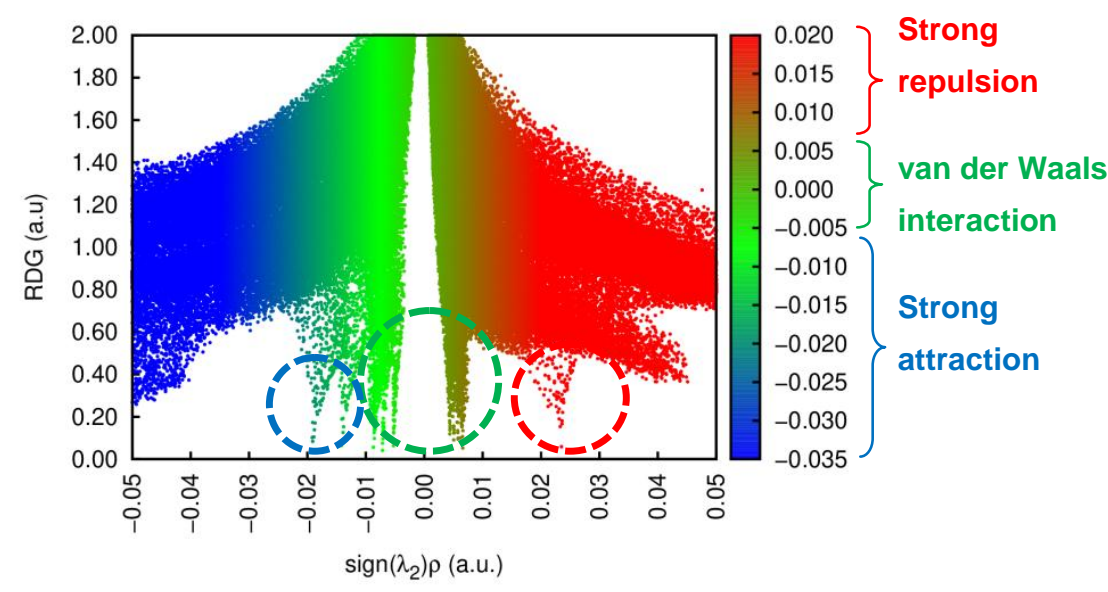

Fig. 6. Representation of different types of interactions in $2 \mathrm{~A} 5 \mathrm{PCoCl}_{4}$ compound (a). The map of Reduced Density Gradient (RDG) defines the interaction limits for $2 \mathrm{~A} 5 \mathrm{PCoCl}_{4}$ (b). 


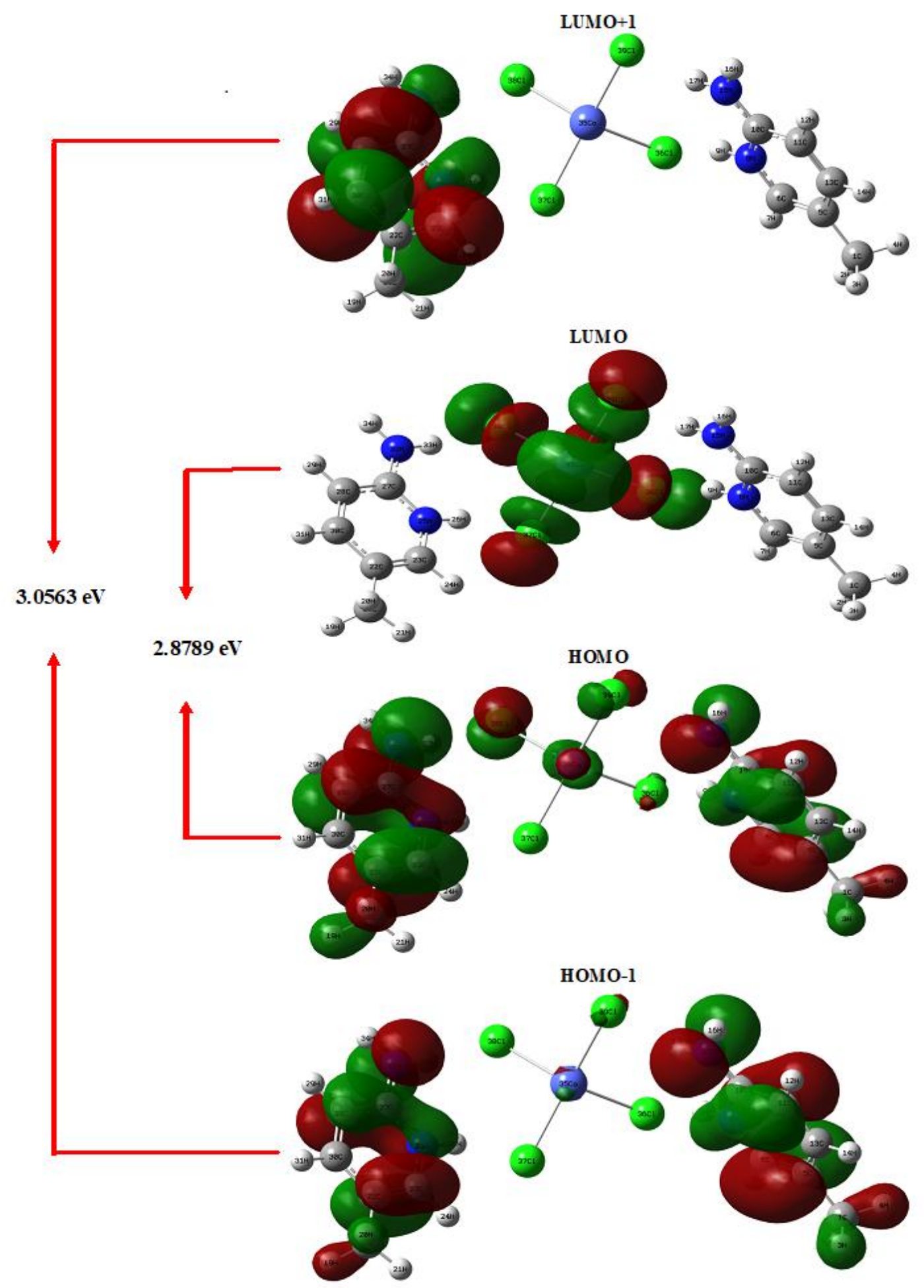

Fig. 7. The frontier molecular orbitals of $2 \mathrm{~A} 5 \mathrm{PCoCl}_{4}$ computed with TD-DFT (B3LYP)/6$311++\mathrm{G}(\mathrm{d}, \mathrm{p})$ in gas phase. 

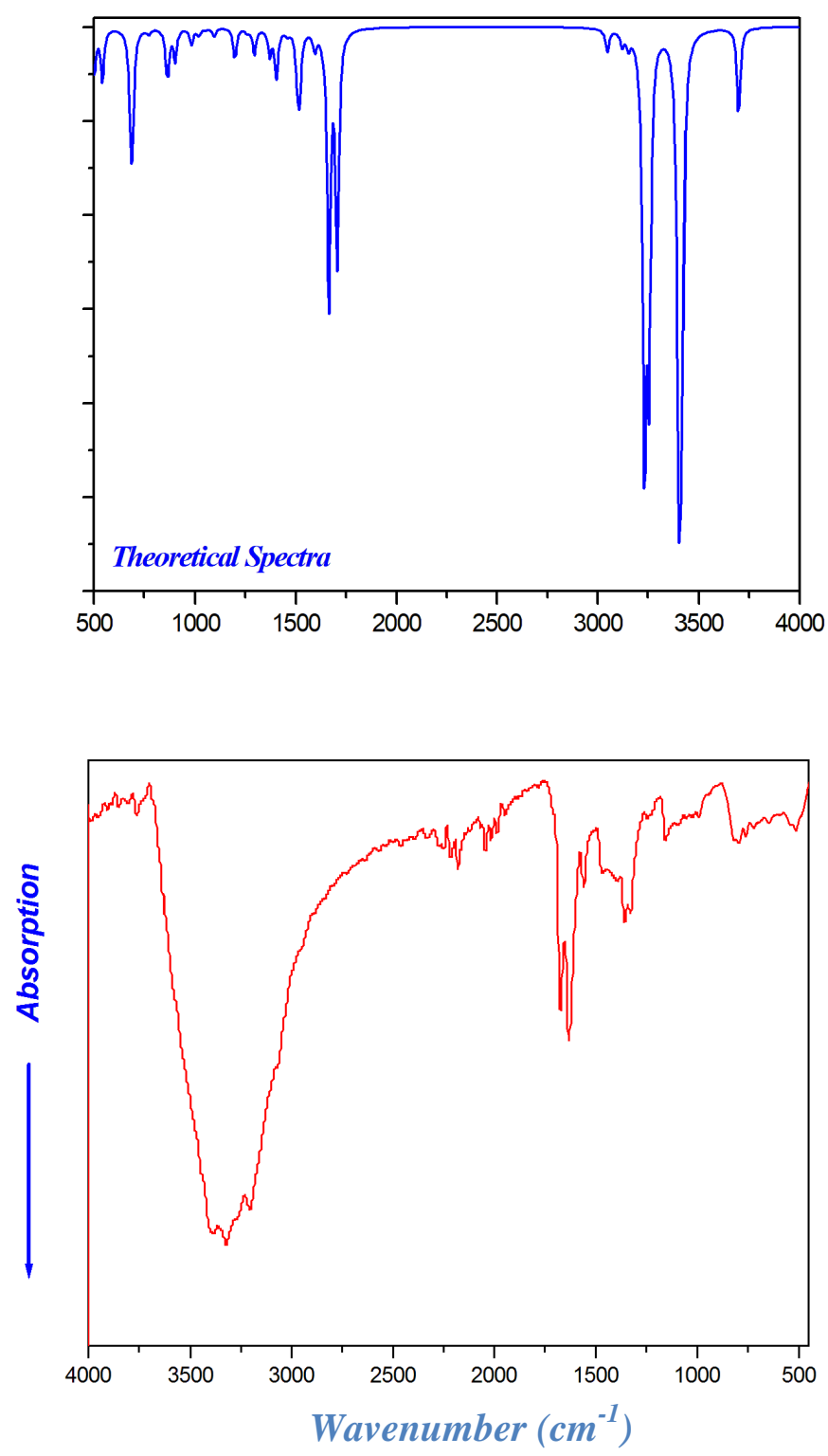

Fig. 8. Theoretical (blue) and experimental (red) IR spectra of $2 \mathrm{~A} 5 \mathrm{PCoCl}_{4}$. 


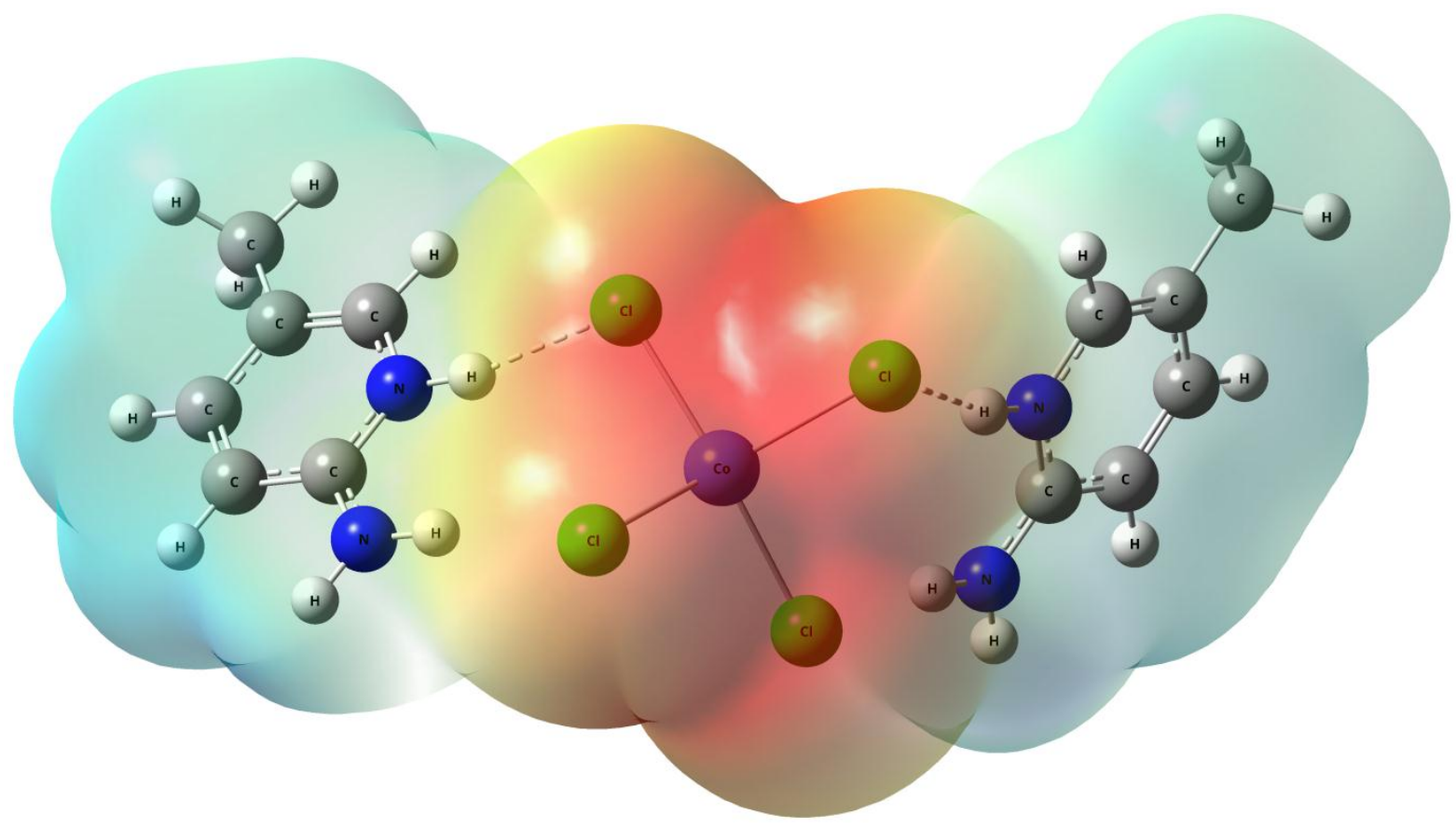

Fig. 9. Molecular Electrostatic Potentials (MEP) surface mapped of $2 \mathrm{~A} 5 \mathrm{PCoCl}_{4}$. 


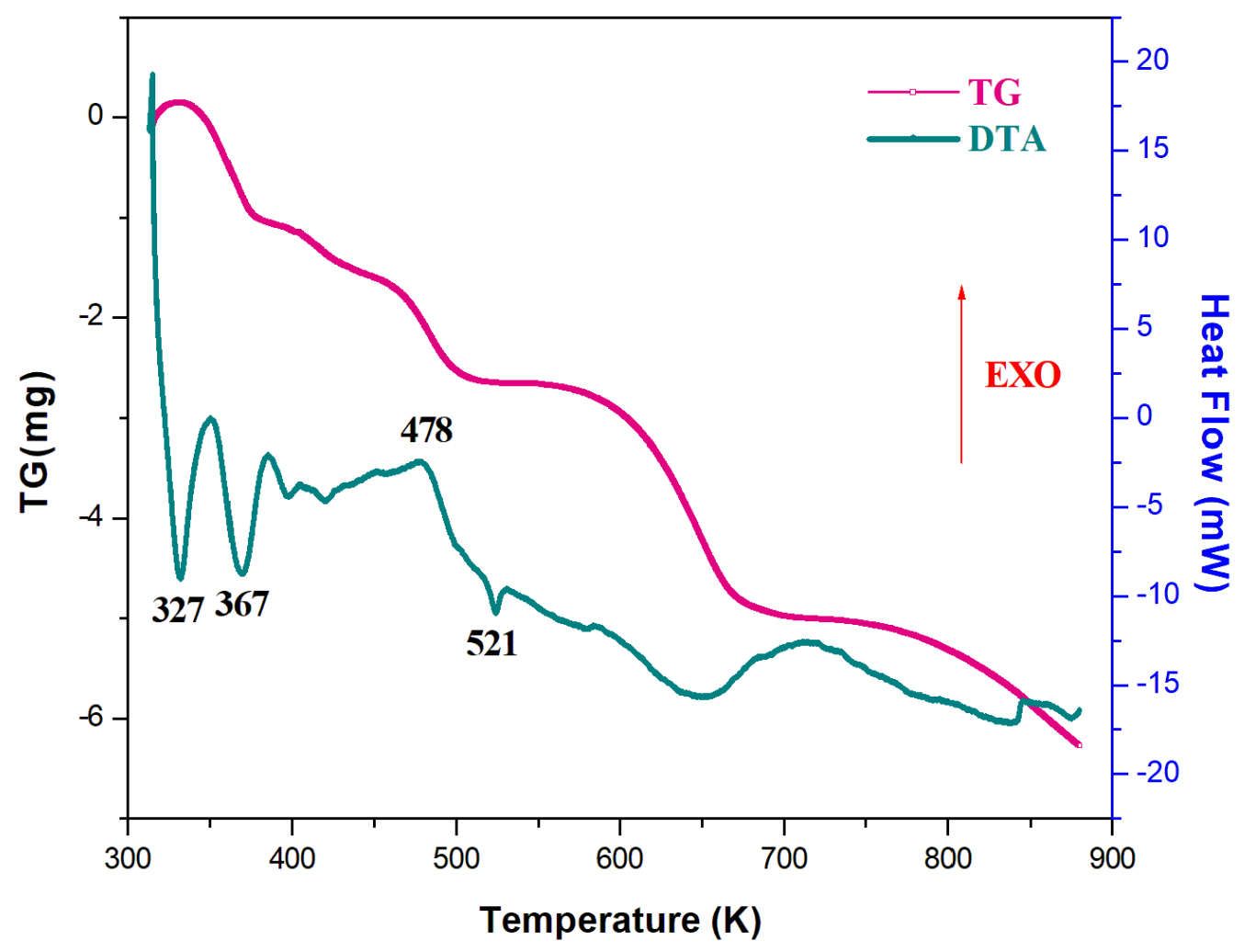

Fig. 10. DTA and TG curves of $2 \mathrm{~A} 5 \mathrm{PCoCl}_{4}$. 


\section{Table 1}

Crystal data and experimental parameters used for the intensity data collection strategy and final results of the structure determination.

\section{Temperature}

Empirical formula

Formula weight $\left(\mathrm{g} \mathrm{mol}^{-1}\right)$

Crystal system

Space group

A

$\mathrm{b}$

c

$\beta$

Z

V

$\mathrm{F}(000)$

$\mu(\operatorname{Mo~K} \alpha)$

Index ranges

Reflections collected

Independent reflections

Reflections with $\mathrm{I}>2 \sigma(\mathrm{I})$

$\mathrm{R}_{\text {int }}$

Absorption correction: multi-scan

Refined parameters

$\mathrm{R}\left[\mathrm{F}^{2}>2 \sigma\left(\mathrm{F}^{2}\right)\right]$

$\mathrm{w} R\left(\mathrm{~F}^{2}\right)$

Goodness of fit

$\Delta \rho_{\max }=0.05 \mathrm{e} \AA^{-3}$
$150 \mathrm{~K}$

$\left(\mathrm{C}_{6} \mathrm{H}_{9} \mathrm{~N}_{2}\right)_{2}\left[\mathrm{CoCl}_{4}\right]$

184.2

Monoclinic

$\mathrm{P} 2{ }_{1} / \mathrm{c}$

$8.0734(6) \AA$

14.6297 (11) §

15.6913 (11) ̊

$103.034(4)^{\circ}$

4

$1805.6(2) \AA^{3}$

852

$0.71073 \AA$

$-9<\mathrm{h}_{\max }<10,-14<\mathrm{k}_{\max }<18,-20<\mathrm{l}_{\max }<16$

15135

4139

3126

0.033

$\mathrm{T}_{\min }=0.697, \mathrm{~T}_{\max }=0.806$

210

0.033

0.076

1.06

$\Delta \rho_{\min }=-0.41 \mathrm{e} \AA^{-3}$ 
Table 2

Hydrogen-bond geometry $\left(\AA,^{\circ}\right)$

\begin{tabular}{lllll}
\hline $\mathrm{D}-\mathrm{H} \cdots \mathrm{A}$ & $\mathrm{D}-\mathrm{H}$ & $\mathrm{H} \cdots \mathrm{A}$ & $\mathrm{D} \cdots \mathrm{A}$ & $\mathrm{D}-\mathrm{H} \cdots \mathrm{A}$ \\
\hline $\mathrm{N} 1-\mathrm{HN} 1 \cdots \mathrm{Cl} 1$ & $0.89(3)$ & $2.34(3)$ & $3.214(2)$ & $170(3)$ \\
$\mathrm{N} 2-\mathrm{H} 2 \mathrm{~A} \cdots \mathrm{Cl} 4$ & $0.84(3)$ & $2.68(3)$ & $3.369(3)$ & $140(3)$ \\
$\mathrm{N} 2-\mathrm{H} 2 \mathrm{~B} \cdots \mathrm{Cl} 3^{\mathrm{i}}$ & $0.84(3)$ & $2.50(3)$ & $3.308(3)$ & $163(3)$ \\
$\mathrm{N} 3-\mathrm{HN} 3 \cdots \mathrm{Cl} 3$ & $0.86(2)$ & $2.73(2)$ & $3.478(2)$ & $146(2)$ \\
$\mathrm{N} 3-\mathrm{HN} 3 \cdots \mathrm{Cl} 2$ & $0.86(2)$ & $2.75(2)$ & $3.374(2)$ & $130(2)$ \\
$\mathrm{N} 4-\mathrm{H} 4 \mathrm{~A} \cdots \mathrm{Cl} 3$ & $0.79(3)$ & $2.46(3)$ & $3.230(3)$ & $164(3)$ \\
$\mathrm{N} 4-\mathrm{H} 4 \mathrm{~B} \cdots \mathrm{Cl} 1^{\mathrm{ii}}$ & $0.79(3)$ & $2.52(3)$ & $3.303(3)$ & $176(3)$ \\
$\mathrm{C} 3-\mathrm{H} 3 \cdots \mathrm{Cl}{ }^{\mathrm{iii}}$ & 0.95 & 2.75 & $3.688(3)$ & 170 \\
$\mathrm{C} 6-\mathrm{H} 6 \cdots \mathrm{Cl} 3^{\mathrm{iv}}$ & 0.95 & 2.86 & $3.716(3)$ & 151 \\
$\mathrm{C} 12-\mathrm{H} 17 \cdots \mathrm{Cl} 4^{\mathrm{v}}$ & 0.95 & 2.81 & $3.754(3)$ & 173 \\
\hline
\end{tabular}

Symmetry codes: (i) $\mathrm{x}-1, \mathrm{y}, \mathrm{z}$; (ii) $-\mathrm{x}+1, \mathrm{y}+1 / 2,-\mathrm{z}+1 / 2$; (iii) $\mathrm{x},-\mathrm{y}+1 / 2, \mathrm{z}+1 / 2$; (iv) $-\mathrm{x},-\mathrm{y}+1$, $-\mathrm{z}+1 ;(\mathrm{v})-\mathrm{x}+1,-\mathrm{y}+1,-\mathrm{z}$. 